\title{
Metformin Promotes Anxiolytic and Antidepressant-Like Responses in Insulin-Resistant Mice by Decreasing Circulating Branched-Chain Amino Acids
}

\author{
Juliane Zemdegs, ${ }^{1 \star}$ Hugo Martin, ${ }^{2 \star}$ Hiranya Pintana, ${ }^{1,3 *}$ Sebastien Bullich, ${ }^{1}$ Stella Manta, ${ }^{1}$ Marie A. Marqués, ${ }^{4}$ \\ Cédric Moro, ${ }^{4}$ Sophie Layé, ${ }^{2}$ Fabien Ducrocq, ${ }^{2}$ Nipon Chattipakorn, ${ }^{3}$ Siriporn C. Chattipakorn, ${ }^{3}$ Claire Rampon, ${ }^{1}$ \\ Luc Pénicaud, ${ }^{5}$ Xavier Fioramonti, ${ }^{2 \#}$ and Bruno P. Guiard ${ }^{1,6^{\#}}$ \\ ${ }^{1}$ Centre de Recherches sur la Cognition Animale, Centre de Biologie Intégrative, Université de Toulouse, CNRS, 31000 Toulouse, France, ${ }^{2}$ Université de \\ Bordeaux, Institut National de la Recherche Agronomique, Bordeaux INP, NutriNeuro, UMR 1286, F-33000 Bordeaux, France, ${ }^{3}$ Neurophysiology Unit, \\ Cardiac Electrophysiology Research and Training Center, Faculty of Medicine, Chiang Mai University, Chiang Mai 50200, Thailand, ${ }^{4}$ INSERM, Paul Sabatier \\ University, UMR 1048, Institute of Metabolic and Cardiovascular Diseases, Obesity Research Laboratory, 31000 Toulouse, France, ${ }^{5}$ UMR STROMALab, \\ Université de Toulouse, CNRS ERL5311, École Française du Sang, Institut National Polytechnique-École Nationale Vétérinaire de Toulouse, INSERM \\ U1031, BP 84225, F-31432, 31000 Toulouse Cedex 4, France, and 'Faculté de Pharmacie, Université Paris Sud, Université Paris-Saclay, 92290 Chatenay- \\ Malabry, France
}

Epidemiological studies indicate that insulin resistance (IR), a hallmark of type 2 diabetes, is associated with an increased risk of major depression. Here, we demonstrated that male mice fed a high-fat diet (HFD) exhibited peripheral metabolic impairments reminiscent of IR accompanied by elevated circulating levels of branched-chain amino acids (BCAAs), whereas both parameters were normalized by chronic treatment with metformin (Met). Given the role of BCAAs in the regulation of tryptophan influx into the brain, we then explored the activity of the serotonin (5-HT) system. Our results indicated that HFD-fed mice displayed impairment in the electrical activity of dorsal raphe 5-HT neurons, attenuated hippocampal extracellular 5-HT concentrations and anxiety, one of the most visible and early symptoms of depression. On the contrary, Met stimulated 5-HT neurons excitability and 5-HT neurotransmission while hindering HFD-induced anxiety. Met also promoted antidepressant-like activities as observed with fluoxetine. In light of these data, we designed a modified HFD in which BCAA dietary supply was reduced by half. Deficiency in BCAAs failed to reverse HFD-induced metabolic impairments while producing antidepressant-like activity and enhancing the behavioral response to fluoxetine. Our results suggest that Met may act by decreasing circulating BCAAs levels to favor serotonergic neurotransmission in the hippocampus and promote antidepressant-like effects in mice fed an HFD. These findings also lead us to envision that a diet poor in BCAAs, provided either alone or as add-on therapy to conventional antidepressant drugs, could help to relieve depressive symptoms in patients with metabolic comorbidities.

Key words: branched-chain amino acids; depression; hippocampus; insulin resistance; metformin; serotonin

\section{Significance Statement}

Insulin resistance in humans is associated with increased risk of anxiodepressive disorders. Such a relationship has been also found in rodents fed a high-fat diet (HFD). To determine whether insulin-sensitizing strategies induce anxiolytic- and/or antidepressant-like activities and to investigate the underlying mechanisms, we tested the effects of metformin, an oral antidiabetic drug, in mice fed an HFD. Metformin reduced levels of circulating branched-chain amino acids, which regulate tryptophan uptake within the brain. Moreover, metformin increased hippocampal serotonergic neurotransmission while promoting anxiolytic- and antidepressant-like effects. Moreover, a diet poor in these amino acids produced similar beneficial behavioral property. Collectively, these results suggest that metformin could be used as add-on therapy to a conventional antidepressant for the comorbidity between metabolic and mental disorders. 


\section{Introduction}

Insulin resistance (IR), defined as declined sensitivity of tissues to the action of insulin, is associated with the development of serious health concerns such as overweight, hypertension, hyperlipidemia, cardiovascular disease, and type 2 diabetes (T2D). Evidence also suggests the existence of a positive correlation between IR and major depression (Rasgon and Kenna, 2005). Indeed, the induction of IR in rats or mice, using prolonged exposure to high-fat diet (HFD), causes some hallmark symptoms of depression including anxiety, anhedonia, and despair (Miyata et al., 2004; Ho et al., 2012; André et al., 2014; Gupta et al., 2014; Dutheil et al., 2016; Yang et al., 2016; Zemdegs et al., 2016; Hassan et al., 2018) and exacerbates behavioral abnormalities observed in animal models of depression (Abildgaard et al., 2011; Liu et al., 2014).

Although the neurobiological mechanisms underlying the relationship between IR and depression have yet to be identified, impairments of brain plasticity have been incriminated. In humans, associations between the severity of IR and the reduction of brain volume have been unveiled (Last et al., 2007; Phillips et al., 2018). In keeping with these results, mice or rats developing IR display deficits in adult hippocampal neurogenesis (Lindqvist et al., 2006; Stranahan et al., 2008; Lang et al., 2009; Park et al., 2010) in a manner similar to that observed in animal models of depression (Surget et al., 2008; David et al., 2009). In marked contrast, insulin-sensitizing strategies exert neuroprotective/neurotrophic effects in rodents (Zhong et al., 2018). This has been reported with the antidiabetic agents liraglutide, glyburide, and metformin (Wang et al., 2012; Su et al., 2017; Weina et al., 2018). Given the beneficial role of the serotonin (5-HT) system in the enhancement of brain plasticity (Quesseveur et al., 2013), the possibility that deficits in 5-HT neurotransmission underlie the comorbidity between T2D/IR and depression, has been raised. Consistent with this hypothesis, decreased levels of tryptophan were detected in the CNS of patients with T2D (Kloiber et al., 2010; HerreraMarquez et al., 2011) or in rodents fed an HFD (Kim et al., 2013; Derkach et al., 2015). Using intracerebral microdialysis, we showed that mice fed an HFD displayed lower basal hippocampal extracellular 5-HT concentrations (Zemdegs et al., 2016). Exaggerated stimulation of the monoamine oxidase activity - the enzyme responsible for 5-HT degradation-or the indoleamine 2,3-dioxygenase-the enzyme that metabolizes tryptophan along the kynurenine pathway-are putative explanations for such neurochemical changes (André et al., 2014; Dinel et al., 2014; Gupta et al., 2014). We recently proposed that an increased sensitivity of inhibitory somatodendritic $5-\mathrm{HT}_{1 \mathrm{~A}}$ autoreceptors in the dorsal raphe (DR) could be an alternative mechanism by

Received Nov. 12, 2018; revised May 7, 2019; accepted May 15, 2019.

Author contributions: X.F. and B.P.G. designed research; J.Z., H.M., H.P., S.B., S.M., M.A.M., C.M., F.D., X.F., and B.P.G. performed research; J.Z., H.P., S.M., S.L., N.C., S.C.C., C.R., L.P., X.F., and B.P.G. analyzed data; X.F. and B.P.G. wrote the paper.

B.P.G. received a fellowship from the "Société Francophone du Diabète (SFD). The salary for J.Z. was supported by the program Ciência sem Fronteiras funded by the National Council for Scientific and Technological Development (CNPq) and H.P. by the Royal Golden Jubilee PhD Program (PHD/0025/2555:HP\&SCC). H.M. is supported by a fellowship from INRA-Région Nouvelle Aquitaine. S.C.C. is supported by TRF:RTA6080003. N.C. is supported by a NSTDA Research Chair Grant from the National Science and Technology Development Agency, Thailand. We thank the Mouse Behavioural Phenotyping Core (Center of Integrative Biology, Toulouse, France) and more particularly Sebastien Lopez for expertise and assistance in setting up the behavioral apparatus and procedures

*J.Z., H.M., and H.P. contributed equally to the study.

\#X.F. and B.P.G. codirected this study.

The authors declare no competing financial interests.

Correspondence should be addressed to Bruno P. Guiard at bruno.guiard@univ-tlse3.fr.

https://doi.org/10.1523/JNEUROSCI.2904-18.2019

Copyright $\odot 2019$ the authors
Table 1. Composition of the standard and high-fat diets

\begin{tabular}{lcccc}
\hline Diet composition & STD & HFD & $\begin{array}{c}\text { HFD- } \\
\text { BCAA }\end{array}$ & $\begin{array}{c}\text { HFD- } \\
\text { BCAA }^{+/-}\end{array}$ \\
\hline Proteins (kcal\%) & 26 & 20 & 20 & 19 \\
Carbohydrates (kcal\%) & 60 & 35 & 34 & 35 \\
Lipids (kcal\%) & 3 & 45 & 46 & 46 \\
Amino acids (g/kg) & & & & \\
$\quad$ BCAAs & & & & 9.35 \\
$\quad$ Leucine & 18.7 & 18.7 & 18.7 & 5.85 \\
$\quad$ Isoleucine & 11.7 & 11.7 & 11.7 & 7 \\
$\quad$ Valine & 14 & 14 & 14 & 2.3 \\
$\quad$ Tryptophan & 1.9 & 2.1 & 2.3 & 4590 \\
Energy content (kcal/kg dry diet) & 2790 & 4720 & 4570 & \\
\hline
\end{tabular}

which IR might hinder hippocampal serotonergic transmission (Zemdegs et al., 2016). Despite these possibilities, the role of branched-chain amino acids [BCAAs; leucine (Leu), isoleucine (Ile), and valine (Val)] in the relationship between IR and brain extracellular 5-HT concentrations is gaining interest. Indeed, elevated circulating BCAA levels predict the severity of IR (Newgard et al., 2009; Gannon et al., 2018) while limiting the uptake of tryptophan into the brain through the blood-brain barrier (BBB) by the large neutral amino acid transporter 1 (LAT1; Pardridge, 1998). Thus, the rate of 5-HT production may be affected by BCAAs, thereby leading to anxiodepressive symptoms, as shown in clinical (Fellendorf et al., 2018) and preclinical studies (Coppola et al., 2013; Scaini et al., 2014; Asor et al., 2015).

On this backdrop, the present study determined whether metformin (an insulin-sensitizing drug belonging to the class of biguanides) exerts beneficial effects on glucose metabolism, on the electrical activity of DR 5-HT neurons, on the 5-HT release at the nerve terminals, and on emotional behavior in a mouse model of comorbid T2D/IR and depression. Moreover, given the association among BCAAs, IR, and depression, and in light of their negative impact on 5-HT neurotransmission, we also tested the possibility that the antidepressant-like effects of metformin rely on an attenuation of circulating BCAA levels.

\section{Materials and Methods}

Animals, diets, and drugs. The 5- to 7-week-old C57BL/6J male mice (Elevages Janvier Farms) were housed four to five mice per cage under standard conditions with a $12 \mathrm{~h}$ light/dark cycle. After 1 week of acclimatization, mice were randomly assigned to receive free access to a standard diet (STD; STD A04, SAFE), an HFD (D12451, Research Diets) or a half-BCAA-HFD (HFD-BCAA ${ }^{+/-}$; MD.1610 version, ENVIGO) up to 16 weeks (Table 1 ). We ensured that tryptophan quantity, the precursor for 5-HT synthesis, was equivalent between STDs and HFDs. In a specific experiment, STD and HFD mice were chronically administered with the insulin-sensitizing agent metformin at the active dose of $300 \mathrm{mg} / \mathrm{kg} / \mathrm{d}$ (Sigma-Aldrich) or the selective serotonin reuptake inhibitor (SSRI) fluoxetine (Flx) at a dose of $18 \mathrm{mg} / \mathrm{kg} / \mathrm{d}$ (Biotrend Chemikalien). Both drugs were dissolved and given in the drinking water. The water consumption per mouse per day $(24 \mathrm{~h})$ was monitored during the course of treatments. Because daily water consumption might have differed between STD and HFD mice, metformin and fluoxetine concentrations in drinking water were adjusted accordingly to achieve comparable dosing. The purpose of giving the metformin and fluoxetine in drinking water was to maintain a constant level of these pharmacological compounds. For example, metformin is typically given to patients in an extended-release form so that its effects can be sustained over long durations. All experimental procedures were conducted in accordance with the European directive 2010/ 63/UE and were approved by the French Ministry of Research and local ethic committees (C2EA Grand Campus de Dijon $N^{\circ} 105$, APAFIS \#12342-2017082111489451 v6, and CE2A Université de Bordeaux N50, Apafis \#8928). 
A

$$
\begin{aligned}
& \text {-O- STD-Veh O- HFD-Veh } \\
& \text {-O- HFD-Met }
\end{aligned}
$$
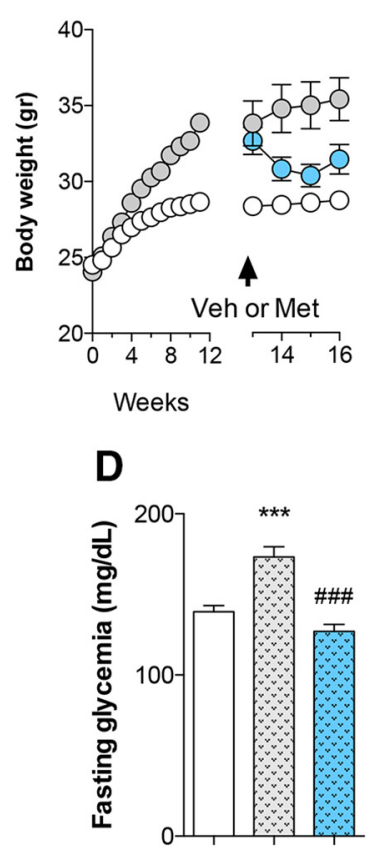

G

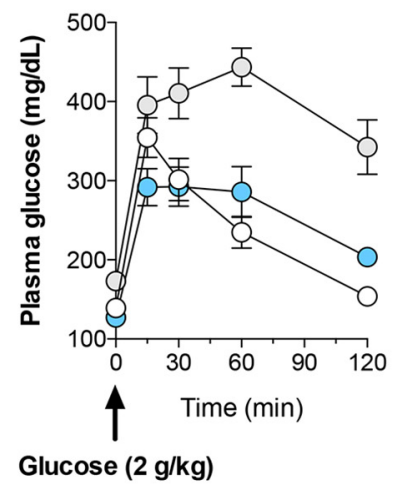

E

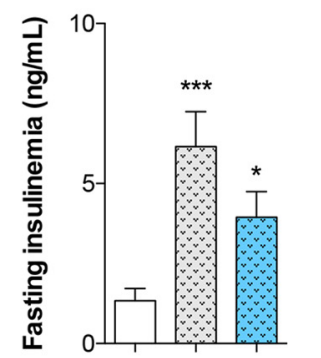

$\mathbf{F}$

H

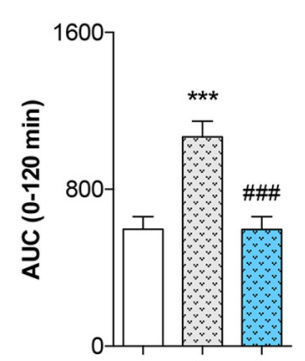

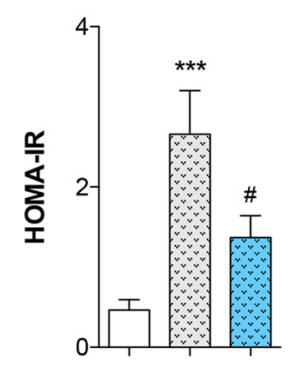
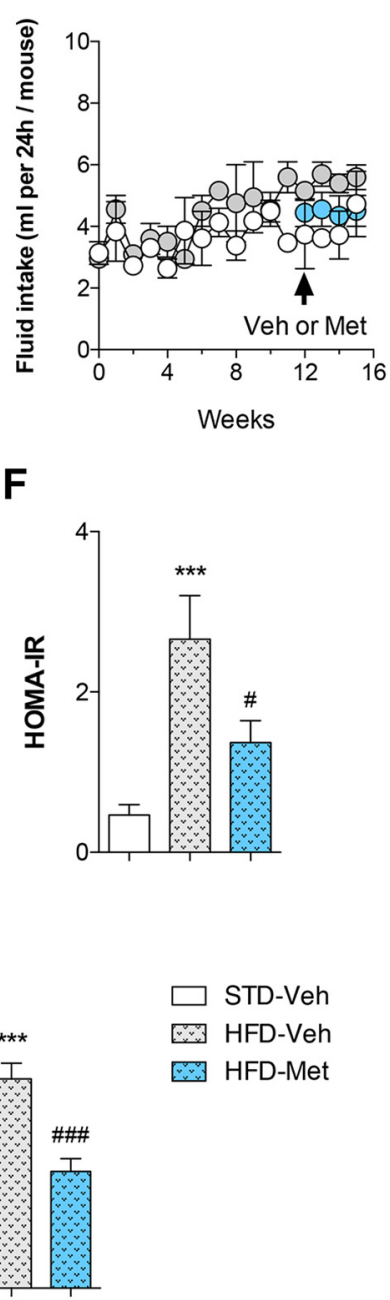

Figure 1. Chronic administration of metformin reverses HFD-induced glucose metabolism impairment. Two groups of mice were fed an HFD for 16 weeks and chronically treated with Met $(300 \mathrm{mg} / \mathrm{kg}$ ) or its Veh in the drinking water for the last 4 weeks. The control group of mice was fed an STD and administered the Veh. $\boldsymbol{A}-\boldsymbol{H}$, Data are the mean \pm SEM of body weight from week 0 to week $16(\boldsymbol{A})$, final body weight $\left(F_{(2,27)}=10.4 ; p=0.0004 ; \boldsymbol{B}\right)$, fluid intake $(\boldsymbol{C})$, basal fasting glycemia $\left(F_{(2,27)}=23.9 ; p=0.0001\right.$; $\boldsymbol{D})$, basal fasting insulinemia $\left(F_{(2,27)}=10.1 ; p=0.0008 ; \boldsymbol{E}\right), \operatorname{HOMA}-\operatorname{IR}\left(F_{(2,27)}=11.2 ; p=0.0005 ; \boldsymbol{F}\right)$, and glucose tolerance in response to the intraperitoneal administration of glucose (for $A_{U} C_{0-120}: F_{(2,27)}=24.9 ; p=0.0001 ; 2 \mathrm{~g} / \mathrm{kg} ; \boldsymbol{G}, \boldsymbol{H}$ ). $n=10$ mice/group. ${ }^{*} p<0.05$ and ${ }^{* * *} p<0.001$ : significantly different from the STD-Veh group. \#p $<0.05$ and \#\#\#p $<0.001$ : significantly different from the HFD-Veh group.

Metabolic parameters: glucose tolerance test. Animals were individually housed, weighed, and fasted for $5 \mathrm{~h}$ with free access to water. Blood glucose level was measured from tail prick (Accu-Chek Performa Glucometer, Roche) at $0 \mathrm{~min}$ (basal), 15, 30, 45, 60, 90, and 120 min after the administration of glucose $(2 \mathrm{~g} / \mathrm{kg})$ in an intraperitoneal glucose tolerance test (ipGTT). During ipGTT, the area under the curve (AUC) was calculated using the coordinate axis set at 100. For plasma insulin levels, blood samples were collected through tail prick in heparinized capillary tubes (Microvette CB 300 K2E, Sarstedt). Blood was centrifuged (10,000 rpm; $10 \mathrm{~min}$ ), and plasma was collected and stored at $-80^{\circ} \mathrm{C}$ before analysis. Insulin was measured using the AlphaLISA method, according to manufacturer instructions (human insulin kit; catalog \#AL204C, PerkinElmer). The homeostasis model assessment (HOMA) of IR (HOMA-IR) scores were calculated from glucose and insulin concentrations obtained from mice after $5 \mathrm{~h}$ of fasting. The following equation was used: fasting blood glucose (in milligrams per deciliter) $\times$ fasting insulin (in nanograms per milliliter)/405. HOMA-IR $\geq 2.8$ represents an insulin resistance state (Matthews et al., 1985).

Plasma amino acids analysis. The BCAA concentration from plasma samples was measured using a BCAA (leucine, isoleucine, and valine) assay kit (catalog \#MAK003, Sigma-Aldrich) according to manufacturer instructions using a coupled enzyme reaction, which results in a colorimetric $(450 \mathrm{~nm})$ product, proportional to the BCAA present.

In vivo single-unit recordings of 5-HT neurons in the dorsal raphe nucleus. Mice were anesthetized with chloral hydrate $(400 \mathrm{mg} / \mathrm{kg}$, i.p.) and placed in a stereotaxic frame with the skull positioned horizontally. To maintain a full anesthesia, chloral hydrate supplements of $100 \mathrm{mg} / \mathrm{kg}$, i.p., were given as needed. Extracellular recordings in the DR were performed using single glass micropipettes (Stoelting Europe) pulled on a pipette puller (Narishige) and preloaded with a $2 \mathrm{M} \mathrm{NaCl}$ solution (impedances from 2.5 to $5 \mathrm{M} \Omega$ ). Micropipettes were positioned $0.2-0.5 \mathrm{~mm}$ posterior to the interaural line on the midline and lowered into the DR, attained at a depth between 2.5 and 3.5 $\mathrm{mm}$ from the brain surface. 5-HT neurons were identified using the following criteria: a slow $(0.5-2.5 \mathrm{~Hz})$ and regular firing rate and a long-duration positive action potential. In each mouse, several tracts were performed to measure the spontaneous firing rate of DR 5 -HT neurons. Firing rates were determined by monitoring the average discharge frequency of DR 5-HT neurons under each experimental condition. The number of neurons recorded per track was also determined.

Brain slice patch-clamp recordings of $D R$ 5-HT neurons. Patch-clamp recordings were performed on brain slices from Pet1-cremCherry mice obtained by crossing Pet 1 -cre mice (a gift from Dr. P. Gaspar, Institut du Fer à Moulin, Inserm, UMR-S 839, Paris, France; Kiyasova et al., 2011) with B6.CgGt(ROSA)26Sor ${ }^{\text {tm } 9 \text { (CAG-tdTomato }) H z e / J}$ mice (The Jackson Laboratory). Briefly, 4-monthold mice fed an STD or HFD for 16 weeks were intracardially perfused during the killing of the mice (exagon/lidocaine, $300 / 30 \mathrm{mg} / \mathrm{kg}$, i.p.) with ice-cold NMDG solution [containing the following (in mM): $1.25 \mathrm{NaH}_{2} \mathrm{PO}_{4}, 2.5 \mathrm{KCl}, 7$ $\mathrm{MgCl}_{2}, 20$ HEPES, $0.5 \mathrm{CaCl}_{2}, 28 \mathrm{NaHCO}_{3}, 8$ D-glucose, $5 \mathrm{~L}(+)$-ascorbate, 3 Na-pyruvate, 2 thiourea, $93 \mathrm{NMDG}$, and $93 \mathrm{HCl} 37 \%$; pH 7.3-7.4, osmolarity, 305-310 $\mathrm{mOsM}$ ]. Brains were quickly removed, and $250 \mu \mathrm{m}$ slices containing the DR were prepared with a vibratome (catalog \#VT1000S, Leica) in icecold oxygenated NMDG solution before recovery for 12-15 min into at $34^{\circ} \mathrm{C}$ in the oxygenated NMDG solution. Slices were then transferred at room temperature into an aCSF solution [containing the following (in mM): $124 \mathrm{NaCl}, 2.5 \mathrm{KCl}, 1.25 \mathrm{NaH}_{2} \mathrm{PO}_{4}, 2 \mathrm{MgCl}_{2}, 2.5 \mathrm{CaCl}_{2}, 2.5$ D-glucose, and $25 \mathrm{NaHCO}_{3}$; pH 7.3-7.4, osmolarity, 305-310 mOsM] for at least $1 \mathrm{~h}$.

Slices were transferred in the recording chamber placed under a microscope (Nikon) outfitted for fluorescence and IR-differential interference contrast video microscopy and perfused with oxygenated aCSF at $2-3 \mathrm{ml} / \mathrm{min}$ in the recording chamber. Viable DR 5-HT neurons were 


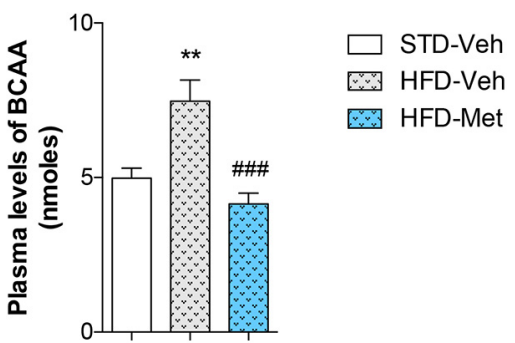

Figure 2. Chronic administration of metformin reverses HFD-induced increase in plasma BCAA levels. Two groups of mice were fed an HFD for 16 weeks and chronically treated with Met $(300 \mathrm{mg} / \mathrm{kg})$ or its Veh in the drinking water for the last 4 weeks. The control group of mice was fed an STD and administered the Veh. Data are the mean \pm SEM of plasma levels of BCAAs (Leu, Val, Iso-Leu; $\left.F_{(2,18)}=13.7 ; p=0.0003\right) . n=7$ mice/group. ${ }^{*} p<0.01$ : significantly different from STD-Veh group. \#\#p < 0.001: significantly different from the HFD-Veh group. visualized with a fluorescence video camera (Nikon). Borosilicate pipettes (4-6 M $\Omega$; outer diameter, $1.5 \mathrm{~mm}$; Sutter Instrument) were filled with an intracellular solution [containing the following (in $\mathrm{mM}$ ): Kgluconate solution: $128 \mathrm{Kgluconate}, 20 \mathrm{NaCl}, 1 \mathrm{MgCl}_{2}$, 1 EGTA, $0.3 \mathrm{CaCl}_{2}$, 2 Na2-ATP, $0.3 \mathrm{Na}$-GTP, 0.2 cAMP, and 10 HEPES; CsCl solution: 150 $\mathrm{CsCl}, 2 \mathrm{MgCl}_{2}$, 1 EGTA, $3 \mathrm{Na} 2-\mathrm{ATP}, 0.3 \mathrm{Na}-\mathrm{GTP}, 0.2 \mathrm{cAMP}$, and 10 HEPES; pH 7.3-7.4, osmolarity, 280-290 mOsM]. Recordings were made using a Multiclamp 700B amplifier, digitized using the Digidata $1440 \mathrm{~A}$ interface and acquired at $2 \mathrm{kHz}$ using pClamp 10.5 software (Molecular Devices). Pipettes and cell capacitances were fully compensated, but the junction potential was not corrected. Intrinsic properties of DR 5-HT neurons were recorded in whole-cell Iclamp mode by injecting a 10 pA current step from -80 to $110 \mathrm{pA}$ on a cell held at $-60 \mathrm{mV}$ by constant current injection. sEPSCs or sIPSCs were recording in Vclamp mode on cells hold at $-60 \mathrm{mV}$. Picrotoxin $(100 \mu \mathrm{M})$ was added to the baths for IPSC recordings. Both sEPSCs and sIPSCs were recorded for $10 \mathrm{~min}$ and analyzed during the last minute of the recording.
A

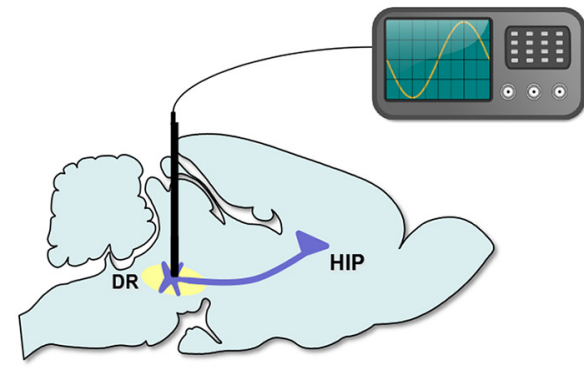

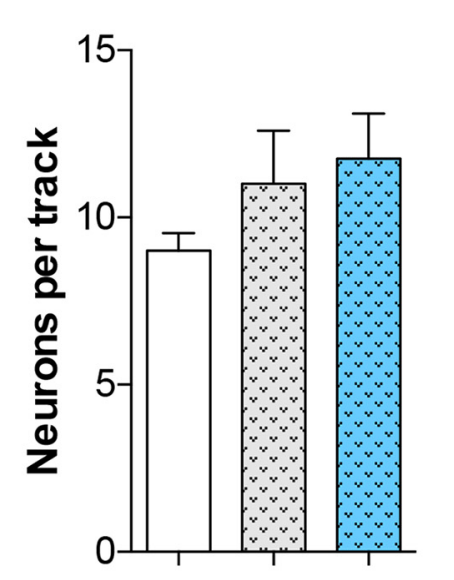

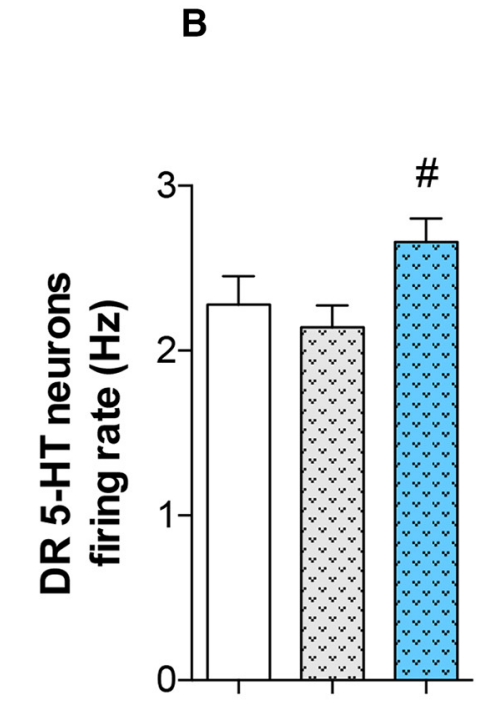

C
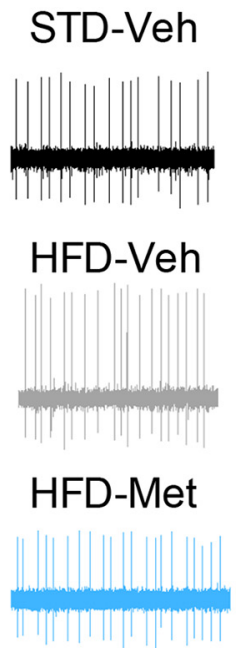

B

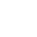


A

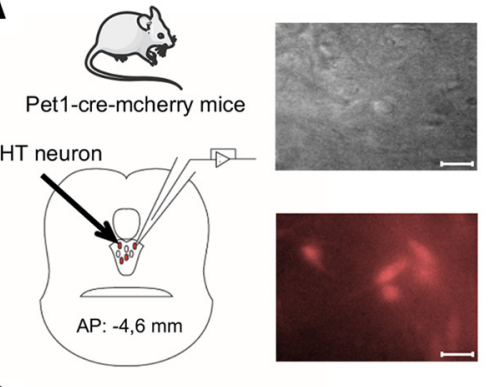

C

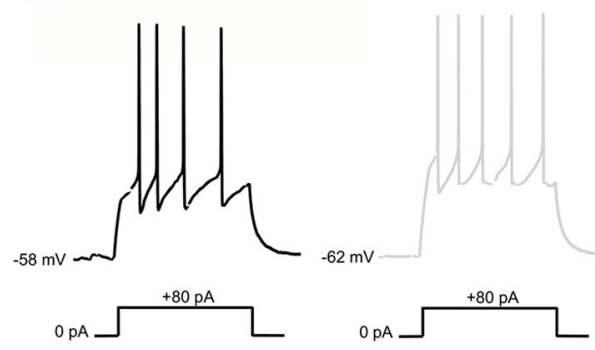

E

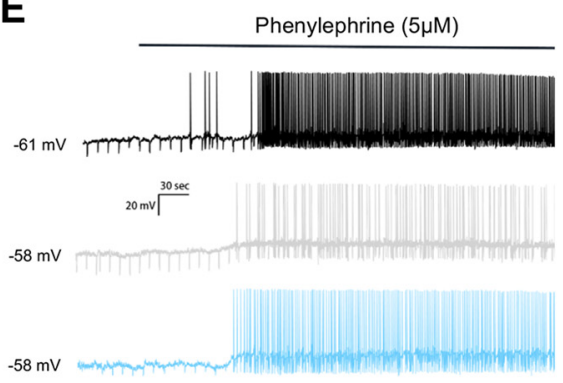

B

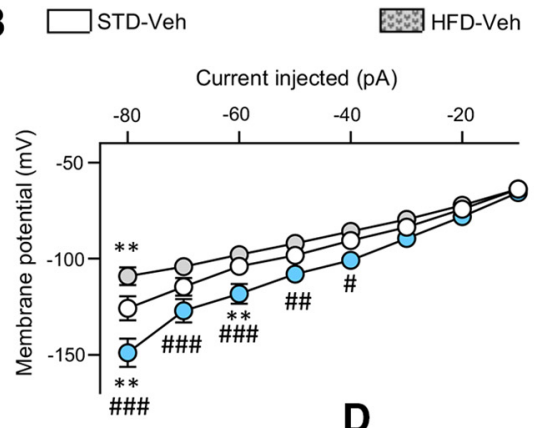

प्रू:

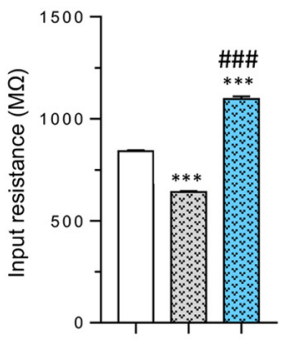

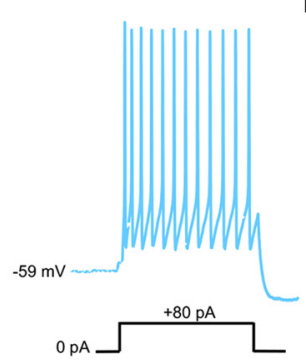

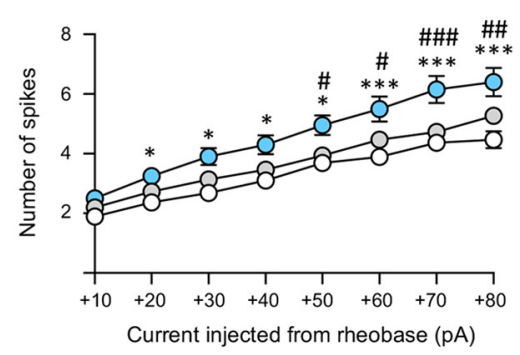

$\mathbf{F}$
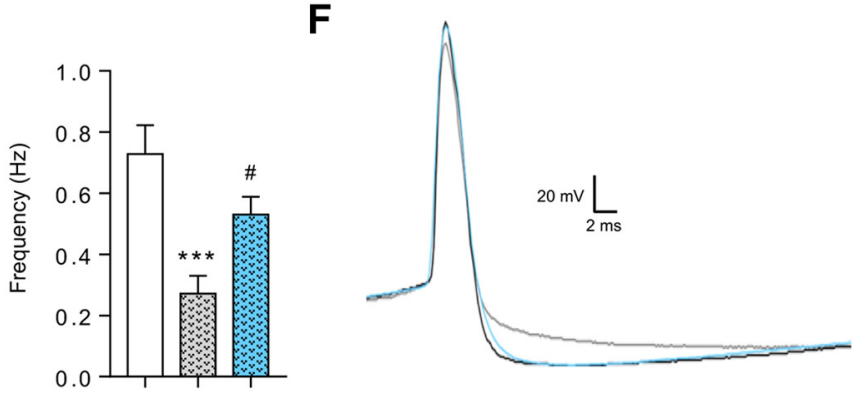

G
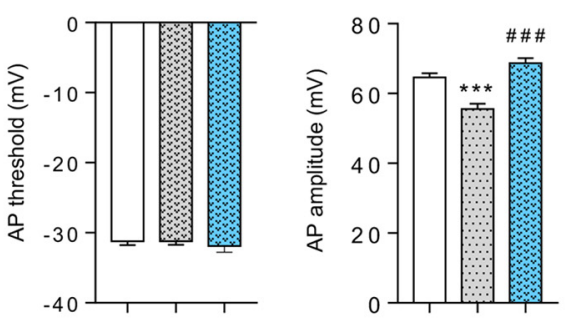
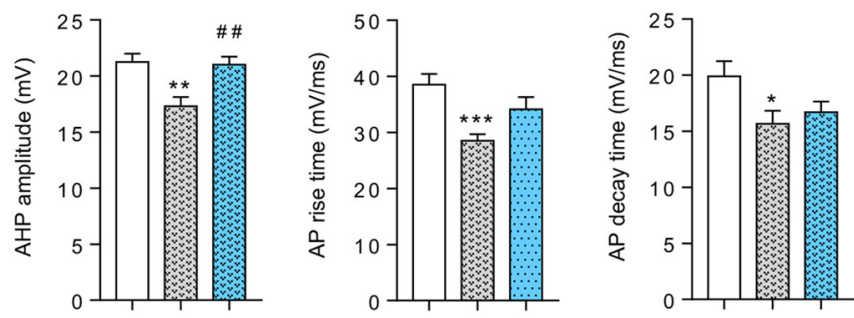

\section{H}

SIPSC

I SEPSC

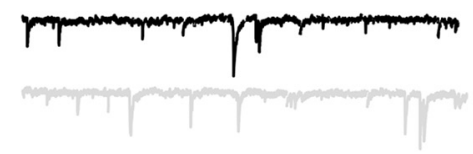

$50 \mathrm{pA} \prod^{20 \mathrm{~ms}}$
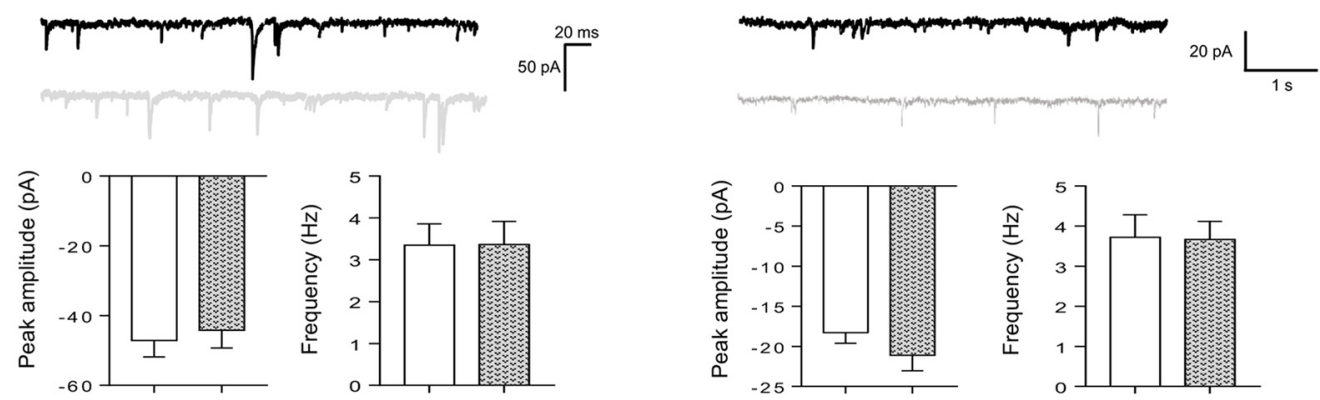

Figure 4. Metformin reverses HFD-induced impairment of the electrical properties of DR 5-HT neurons. A, Two groups of Pet1-cre-mCherry mice were fed an HFD for 16 weeks and chronically treated with Met ( $300 \mathrm{mg} / \mathrm{kg}$ ) or its Veh in the drinking water for the last 4 weeks. The control group of mice was fed an STD and administered the Veh. A, right, Images in bright field (upper panel) or fluorescence (lower panel) of 5-HT neurons expressing the red fluorescent protein mCherry in the DR of Pet1-cre-mCherry mice. The scale bar on each image represents $10 \mu \mathrm{m} \boldsymbol{B}$, Mean membrane potential ( $\boldsymbol{B}$, left) and quantification of the input resistance $(\boldsymbol{B}$, right) in response to hyperpolarizing currents. $\boldsymbol{B}$, left, Data are the mean \pm SEM of membrane potentials in response to hyperpolarizing current step injections (ANOVA: $\left.F_{(14,399)}=7.463 ; p<0.0001\right)$. B , right, Input resistance was calculated using linear regression from an I-V curve according to Ohm's law. Comparison between groups was performed using ANOVA $\left(F_{(2.57)}=754.1 ; p<0.0001\right)$. C $-\boldsymbol{D}$, Representative traces of 5-HT neurons from WT (black), HFD (gray), or HFD-Met (blue) mice in response to depolarizing currents (C).D, Quantification of the number of spikes in response to depolarizing currents from rheobase. Data are the mean $\pm S E M$ of the number of spikes in response to relative current injected (ANOVA: $\left.F_{(16,408)}=3.795 ; p<0.0001\right)$. $\boldsymbol{E}$, Representative traces of 5-HT neurons from STD (black), HFD (gray), and HFD-Met (blue) mice in response to phenylephrine (Figure legend continues.) 
Intracerebral microdialysis in the ventral hippocampus of awake freely moving mice. Mice were implanted with a home-made microdialysis probe in the ventral hippocampus (vHP). Stereotaxic coordinates from bregma were as follows (in mm): antero-posterior (AP), - 2.5; lateral (L), \pm 2.7 ; and dorso-ventral (DV), -3.0 . Twenty-four hours later, probes were connected to a microinjection pump for a continuous perfusion of aCSF (147 mm NaCl, $2.7 \mathrm{~mm} \mathrm{KCl,} 1 \mathrm{~mm} \mathrm{MgCl}$, and $1.2 \mathrm{~mm} \mathrm{CaCl} 2$, adjusted to pH 7.4 with $2 \mathrm{~mm}$ sodium phosphate buffer) containing the serotonin reuptake inhibitor escitalopram $(1 \mu \mathrm{M})$ at a flow rate of 1.5 $\mu \mathrm{l} / \mathrm{min}$. Samples $(15 \mu \mathrm{l})$ were collected every $15 \mathrm{~min}$ and analyzed with a high-performance liquid chromatography system equipped with a 2.6 $\mu \mathrm{m} \mathrm{C18}$ reverse-phase analytical column $(50 \times 3.0 \mathrm{~mm}$; Accucore, Thermo Fisher Scientific) coupled with electrochemical detection (Dionex Ultimate 3000, Thermo Fisher Scientific). The mobile phase containing $150 \mathrm{~mm} \mathrm{NaH}_{2} \mathrm{PO}_{4}, 4.76 \mathrm{~mm}$ citric acid, $50 \mathrm{~mm}$ EDTA, $1.5 \mathrm{~mm}$ SDS, $10 \%$ methanol, and $15 \%$ acetonitrile, adjusted to $\mathrm{pH} 5.6$ with $\mathrm{NaOH}$, was delivered at a flow rate of $0.3 \mathrm{ml} / \mathrm{min}$. The amount of $5-\mathrm{HT}$ in dialysate samples was calculated by measuring the peak heights relative to external standards and was expressed as a percentage of the basal value measured in the four initial fractions. At the end of the experiments, the localization of the microdialysis probes was verified histologically.

Behavioral tests. Animals were tested in different behavioral paradigms starting with the less stressful paradigm and finished with the most stressful one. A $2 \mathrm{~d}$ recovery period between each test was respected.

An open field (OF) test was performed in Plexiglas boxes $(40 \times 40 \mathrm{~cm}$; Mouse Open Field Arena ENV-510, Med Associates) during a $10 \mathrm{~min}$ session. The total ambulatory distance was monitored using the Activity Monitor software (SOF-811, Med Associates) to eliminate any putative bias link to a psychostimulant or a sedative effect.

Elevated plus maze (EPM) was performed in an apparatus manufactured by Ugo Basile, with four 5-cm-wide and 35-cm-long arms, two of which are open: the wall in the closed arms is $15 \mathrm{~cm}$ high. Each mouse was allowed to explore the apparatus for $5 \mathrm{~min}$. Global activity was assessed by measuring the time and number of entries into the open arms for which animals display innate aversion.

Novelty suppressed feeding (NSF) was performed in a white plastic box $(30 \times 60 \mathrm{~cm})$. Mice were food deprived for $24 \mathrm{~h}$ while maintaining water ad libitum. On the day of testing, mice were removed from their home cage and transferred to a new clean cage for $1 \mathrm{~h}$. They were then individually placed in the corner of a box with a food pellet on a white square filter paper at the center of the arena under a bright light $(\sim 60 \mathrm{~W})$. The latency for the animal to approach and take its first bite of the food was recorded (cutoff, $10 \mathrm{~min}$ ). Immediately after the test, the feeding drive of each mouse was assessed by returning it individually to the familiar environment of the home cage and measuring the latency to eat and the amount of food consumed over a period of $5 \mathrm{~min}$. Since each mouse was tested with their respective food pellet, the latter parameter was calculated based on caloric value consumed using the following formula [(pellet weight before (in grams) - pellet weight after (in grams) $\times$ number of calories/gram diet (STD, 2.79 calories/g; HFD, 4.73 calories/

\section{$\leftarrow$}

(Figure legend continued.) application ( $5 \mu \mathrm{M}$; left) and quantification of action potential frequency during the last minute of the recordings (right). Data are the mean \pm SEM of firing rate frequency in response to phenylephrine ( $5 \mu \mathrm{M} ; \mathrm{ANOVA:} F(2,21) \& 10,24 ; p=0.0008) . \boldsymbol{F}, \mathbf{G}$, Representative action potential (AP) of 5-HT neurons from STD (black), HFD (gray), and HFDMet (blue) mice $(\boldsymbol{F})$; and quantification of AP threshold, amplitude, afterhyperpolarization, rise time, and decay time $(G)$. Data are the mean \pm SEM of neuron AP intrinsic properties. ANOVA: AP threshold $\left(F_{(2,60)}=0.3278 ; p=0.7218\right) ;$ AP amplitude $\left(F_{(2,60)}=24.33 ; p<0.0001\right)$; AHP amplitude $\left(F_{(2,60)}=8.657 ; p=0.0005\right) ; A$ P rise time $\left(F_{(2,60)}=8.314 ; p=0.0007\right) ; \mathrm{AP}$ decay time Kruskal-Wallis test $(K=7.149 ; p=0.0280) . H, I$, Representative traces and quantification of the frequency and amplitude of IPSCS $(\boldsymbol{H})$ or EPSCS ( $\boldsymbol{I})$ onto 5 -HT neurons from STD (black) and HFD (gray) mice. Data are the mean \pm SEM of sIPSC frequency (Mann-Whitney test: $U=$ $399.5 ; p=0.9588)$ and peak amplitude $(U=359 ; p=0.4888) . I$, Data are the mean \pm SEM of sEPSC frequency $(U=155.5 ; p=0.7106)$ and peak amplitude (unpaired $t$ test, $p=0.2220$ ). ${ }^{*} p<0.05 ;{ }^{* *} p<0.01$; ${ }^{* * *} p<0.001$ : significantly different from STD-Veh group. $\# p<0.05$; $\# \#<0.01$; \#\#\# <0.001: significantly different from HFD-Veh group. gram)/mouse body weight]. These parameters were determined to ensure the absence of differences in hunger/motivation.

A tail suspension test (TST) was performed using the Tail Suspension Test System (BIOSEB) during a 6 min session. Immobility time was scored as an index of resignation. Mice movements in terms of energy and power in motion were measured to ensure the absence of any locomotor bias.

A splash test (ST) was performed for a 5 min period as previously described (David et al., 2009). After squirting $200 \mu \mathrm{l}$ of a $10 \%$ sucrose solution on the snout of the mouse, grooming time was scored by a single experimenter as an index of self-care.

Statistical analysis. Unpaired Student's $t$ test was used to evaluate the metabolic and behavioral effects of metformin compared with vehicle (Veh) in mice fed an STD. For all other experiments, mice were fed an STD or HFD, and one- or two-way ANOVAs were applied, when appropriate, by post hoc tests (protected least significant difference) using GraphPad Prism (GraphPad Software). In the NSF, we used the Kaplan-Meier survival representation to indicate the fraction of animals not eating during the test. The accepted level of significance was set at $p \leq 0.05$.

\section{Results}

Metformin does not modify glucose metabolism and emotionally related behaviors in mice fed an STD

In the first part of this study, the effects of 4 weeks of administration of Met, an oral antidiabetic drug displaying insulinsensitizing properties, were evaluated on metabolism and behavior in mice fed an STD. Comparing STD-Veh $(n=9)$ and STD-Met $(n=8)$ mice using an unpaired $t$ test, we found no statistical differences between groups on final body weight $(31.5 \pm 0.5$ vs $30.2 \pm 0.6 \mathrm{~g} ; p=0.4)$, fasting glycemia ( $122 \pm 6 \mathrm{vs}$ $110 \pm 4 \mathrm{mg} / \mathrm{dl} ; p=0.1)$, fasting plasma insulin ( $1.3 \pm 0.3$ vs $0.7 \pm$ $0.1 \mathrm{ng} / \mathrm{ml} ; p=0.3)$, HOMA-IR (0.39 \pm 0.09 vs $0.19 \pm 0.03 ; p=$ $0.1)$, and glucose tolerance $\left(\mathrm{AUC}_{0-120}: 565 \pm 57\right.$ vs $597 \pm 105$; $p=0.4$ ). Similarly, at the behavioral level, no significant differences were detected between STD-Veh and STD-Met mice regarding their performances in the EPM (time: $69 \pm 6$ vs $67 \pm 11 \mathrm{~s}$, $p=0.8$; entries in open arms: $7.4 \pm 1$ vs $7.8 \pm 1 \mathrm{~s}, p=0.8)$, the NSF (latency to feed: $163 \pm 19$ vs $202 \pm 46 \mathrm{~s}, p=0.5$ ), and the TST $(88 \pm 6$ vs $78 \pm 8 s, p=0.4)$.

\section{Metformin improves glucose metabolism in mice fed an HFD} We then tested the effects of Met in mice fed an HFD for 16 weeks. Exposure to HFD induced a significantly higher increase in body weight from the 1 st to the 12 th week than that observed in control mice fed an STD. Before the initiation of the different treatments (12th week), HFD groups of mice were balanced, and the average individual weights were similar (Fig. 1A). Four weeks later (16th week), higher body weight was observed in HFD-Veh relative to control mice fed an STD ( $p=0.0003$; Fig. $1 A, B)$, whereas HFDMet mice had lower body weight than HFD-Veh mice $(p=0.02$; Fig. $1 A, B)$. During this period, fluid intake was similar among STD-Veh, HFD-Veh, and HFD-Met mice (Fig. 1C). With respect to the other metabolic measures, an HFD increased fasting glycemia $(p=0.0001)$, insulinemia $(p=0.0006)$, and the HOMA-IR $(p=0.0004)$ relative to controls (Fig. $1 D-F)$. All of these parameters were decreased in HFD-Met mice compared with HDF-Veh mice, albeit not statistically significant for insulinemia $(p=$ $0.0001 ; p=0.13 ; p=0.04$; Fig. $1 D-F)$. In keeping with the latter observations, HFD-Veh mice displayed glucose intolerance $(p=$ $0.0002)$, and this effect was reversed by Met $(p=0.0002$; Fig. $1 G, H)$. Together, these data show that HFD-fed mice displayed obvious metabolic disturbances, whereas chronic treatment with Met reversed these metabolic impairments through insulinsensitizing properties. 

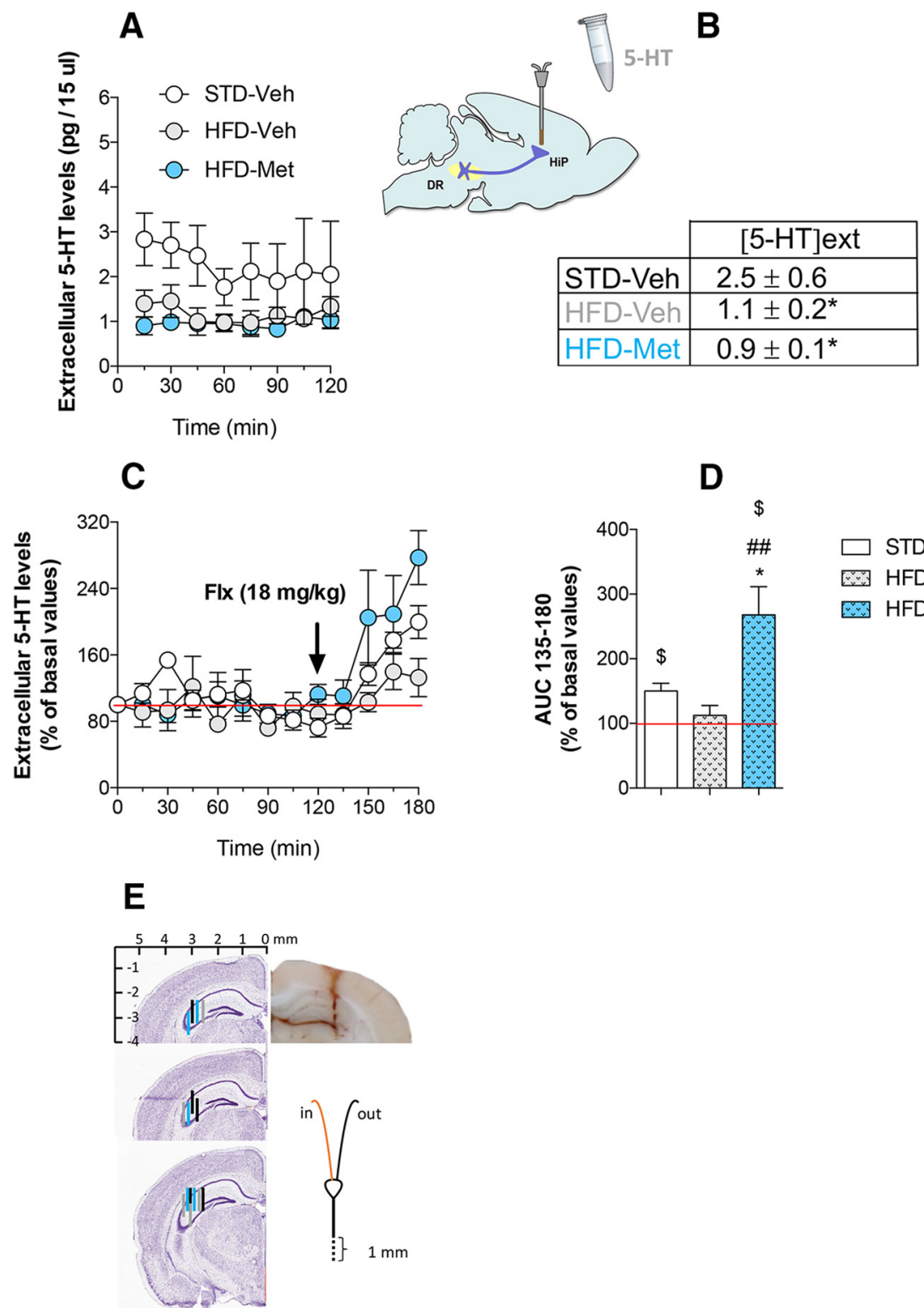

Figure 5. Chronic administration of metformin modulates 5-HT release in the ventral hippocampus of mice fed an HFD. Two groups of mice were fed an HFD for 16 weeks and were chronically treated with Met $(300 \mathrm{mg} / \mathrm{kg}$ ) or its Veh in the drinking water for the last 4 weeks. The control group of mice was fed an STD and administered the Veh. $\boldsymbol{A}, \boldsymbol{B}$, Data are the mean \pm SEM of basal extracellular 5-HT levels in the $\mathrm{vHP}(\mathrm{pg} / 15 \mu \mathrm{l})$ on a $0-120$ min period $\left(F_{(2,13)}=4.5 ; p=0.03\right)$. C, Data are the mean \pm SEM of [5-HT]ext levels in $\mathrm{VHP}$, expressed as percentages of the respective basal values following exposure to an intraperitoneal administration of fluoxetine $(18 \mathrm{mg} / \mathrm{kg}$ ). D, AUC (mean \pm SEM) values calculated for the amount of $5-H T$ in the vHP outflow measured during the 135-180 min after Flx administration and expressed as percentages of baseline $\left(F_{(2,13)}=7.4 ; p=0.007\right)$. E, Coronal sections of a $\mathrm{C} 57 \mathrm{BL} / 6$ mouse brain showing the location of the concentric microdialysis probes tips in the hippocampus. The black, gray, and blue lines indicate the brain zone of the membrane from STD-Veh, HFD-Veh, and HFD-Met mice, respectively. ${ }^{*} p<0.05$ : significantly different from the STD-Veh group. \#\#p < 0.01: significantly different from the HFD-Veh group. $\$ p<0.05$ : significantly different from the $100 \%$ value.

\section{Metformin decreases plasma levels of BCAAs in mice fed an HFD}

Because elevated circulating BCAAs levels have been correlated with the severity of insulin resistance (Gannon et al., 2018) and neurobehavioral abnormalities (Coppola et al., 2013), we measured the plasma levels of these amino acids. As expected, HFDVeh mice displayed a marked increase in plasma BCAAs $(p=$ 0.0038 ) compared with STD-Veh mice, and this rise in plasma BCAA content was significantly attenuated in HFD-Met mice ( $p=0.0003$; Fig. 2).
Metformin positively influences the serotonergic system in mice fed an HFD Because BCAAs share the same transport protein into the brain with aromatic amino acids such as tryptophan, the sole precursor of centrally produced 5-HT, we then questioned the impact of these changes in plasma levels of amino acids on the serotonergic system. We first studied the activity of presumed DR 5-HT neurons using in vivo electrophysiology. Results indicated that the average number of cells recorded per track was not different among the experimental groups (Fig. 3A). However, although the firing rate of DR 5-HT neurons was not modified in HFDVeh mice compared with STD-Veh mice, the statistical analysis revealed a significant increase in the firing rate of these neuronal populations in HFD-Met mice compared with HFD-Veh mice ( $p=$ 0.032; Fig. $3 B, C)$.

Using patch-clamp electrophysiology on brain slices from Pet1-cre-mCherry mice to selectively visualized DR 5-HT neurons (Fig. $4 A$ ), we found decreased input resistance in these neurons in HFDVeh mice compared with STD-Veh mice without modification of the number of spikes evoked by depolarizing currents $(p<0.0001$; Fig. $4 B-D)$. Met treatment increased the input resistance $(p<0.0001$; Fig. $4 B$ ) and the number of spikes in response to depolarizing currents of 5-HT neurons compared with STD- or HFDfed mice $(p<0.0001$; Fig. $4 C, D)$. In HFDVeh mice, an attenuated response to phenylephrine application was also observed ( $p=0.0006$; Fig. $4 E$ ) whereas Met treatment reversed this parameter $(p=$ $0.0339)$. Of particular note are the impairments of some of the intrinsic properties of 5-HT neuron action potentials in HFDVeh mice, which were partially reversed in HFD-Met mice (Fig. $4 F, G$ ). Interestingly, the frequency and amplitude of sEPSCs or sIPSCs in 5-HT neurons was not affected by HFD feeding $(p=0.7106$ and $p=$ 0.2220 for sEPSCs, respectively; $p=$ 0.9588 and $p=0.4888$ for sIPSCs, respectively; Fig. $4 H, I)$. These data suggest that the effects of the diet on the electrical properties of 5-HT neurons were not due to changes in glutamate or GABA presynaptic inputs.

To determine whether changes in electrical properties of DR 5-HT neurons have in vivo consequences on basal extracellular 5 -HT levels ([5-HT] ext) in the vHP, we conducted intracerebral microdialysis experiments (Fig. 5). This brain region is endowed with a dense serotonergic innervation from the DR and is particularly important in anxiolytic-like/antidepressant-like responses. Basal [5-HT] ext levels were significantly decreased in the HFDVeh mice $(p=0.04)$ and HFD-Met mice $(p=0.03$; Fig. $5 A, B)$ compared with STD-Veh mice. Testing the effect of a challenge 
dose of Flx to produce an acute inactivation of the serotonin transporter (SERT), we observed that this pharmacological compound significantly increased the percentage of [5-HT] ext over baseline in STD-Veh and HFD-Met mice ( $p=0.013$ and $p=0.0011$, respectively), but such a response was not apparent in HFD-Veh mice $(p=0.46$; Fig. $5 C, D)$. Interestingly the neurochemical effect of Flx was higher in HFD-Met than that observed in the other groups (Fig. 5C,D).

\section{Metformin promotes anxiolytic/ antidepressant-like activities in mice fed an HFD}

Finally, we sought to determine how these properties reverberated at the behavioral level. The SSRI Flx was used as positive control. We first control the locomotor activity of mice using the OF, and we showed that this parameter was not significantly different between groups (Fig. 6A). In the EPM, HFD-Veh mice displayed decreased time $(p=0.0045)$ and entries in open arms $(p=0.0002)$ compared with STD-Veh mice. These anxiogenic-like responses were partially reversed in HFDMet-treated mice $(p=0.04$ and $p=0.09)$ but not in HFD-Flx-treated mice ( $p=$ 0.99 and $p=0.99$; Fig. $6 B, C)$. In the NSF, an increased latency to feed, which can be also used as a readout for anxiety, was detected in HFD-Veh mice ( $p=0.0001)$. This behavior was significantly attenuated in HFD-Met mice $(p=0.015)$ and HFDFlx mice $(p=0.0001)$ compared with HFD-Veh mice (Fig. 6D). In an attempt to verify that the latter results could not be attributable to changes in hunger, we verified that the latency to eat in the home cage was the same in all experimental groups (Fig. 6E). Interestingly, food home cage consumption based on caloric value consumed was significantly higher in HFD-Veh mice $(p=$ $0.0001)$, HFD-Met mice $(p=0.0001)$, and HFD-Flx mice $(p=$ 0.0001 ) compared with STD-Veh mice (Fig. $6 F$ ), thereby reinforcing the idea that the increased latency to eat during the test was not related to the fact that HFD mice were less starved. We also evaluated other symptoms of depression such as despair in the TST. No changes in the time of immobility was detected in HDF-Veh mice $(p=0.69)$ compared with controls. However, we found a decrease of this parameter in HFD-Met mice $(p=0.04)$ and HFD-Flx mice ( $p=0.04$ ) relative to HFD-Veh mice (Fig. $6 G)$. Overall, these results indicated that mice fed an HFD harbored a robust anxious phenotype. In this model, Met elicited both anxiolytic- and antidepressant-like responses.

BCAA deficiency in diet exerts anxiolytic-/antidepressant-like effects without improvement of glucose metabolism in mice fed an HFD

As Met improves glucose metabolism, decreases plasma BCAA levels, and elicits anxiolytic-/antidepressant-like activities in mice
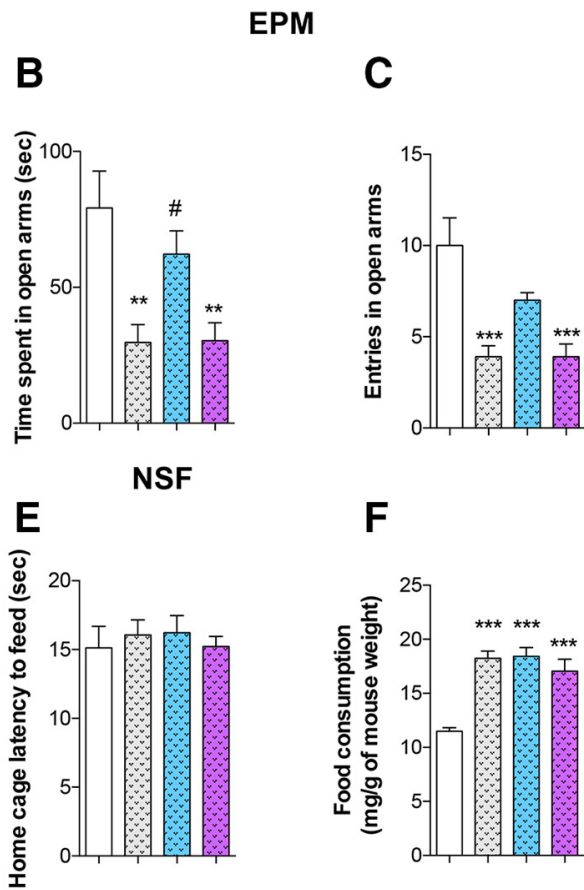

Figure 6. Chronic administration of metformin reverses HFD-induced anxiety-/depressive-like effects. Three groups of mice of mice was fed an STD and administered the Veh. $A-G$, Data are the mean \pm SEM of the total distance traveled in the open $\left.10 \min \left[F_{(3,36)}=2.8 ; p=0.06\right] ; A\right)$, time spent, and number of entries in open arms in the $\operatorname{EPM}\left(F_{(3,36)}=6.7, p=0.0011\right.$ $\left.F_{(3,36)}=0.22, p=0.88 ; \boldsymbol{E}\right)$, food home cage consumption based on caloric value consumed $\left(F_{(3,36)}=17.6 ; p=0.0001 ; \boldsymbol{F}\right)$, and time of immobility in the TST $\left(F_{(3,36)}=6.4 ; p=0.0013 ; \boldsymbol{G}\right) . n=10$ mice/group. ${ }^{* *} p<0.01$ and ${ }^{* * *} p<0.001$ : significantly different from STD-Veh group. \#p $<0.05$, \#\#p $<0.01$ and \#\#\#p <0.001: significantly different from HFD-Veh group.

fed an HFD, we tested the possibility that deficiency in these specific amino acids could exert beneficial effects both on peripheral parameters and neurobehavioral responses. With this prospect, we designed a modified HFD in which the BCAA dietary supply was reduced by half. The plasma levels of BCAAs was reduced by $\sim 40 \%$ in $\mathrm{HFD}-\mathrm{BCAA}^{+/-}$mice compared with HFD$\mathrm{BCAA}^{+/+}$mice $(p=0.0001$; Fig. $7 A)$.

Exposure to HFD-BCAA ${ }^{+/+}$for 16 weeks induced a significant increase in body weight, fasting glycemia, and insulinemia $(p=0.0001 ; p=0.04 ; p=0.04)$; and resulted in a significant glucose intolerance $(p=0.0001)$ compared with control mice fed an STD (Fig. $7 B-G$ ). The same phenotype was observed in HFD$\mathrm{BCAA}^{+/-}$mice $(p=0.0001, p=0.008, p=0.04$, and $p=$ $0.0001)$, and no differences between HFD-BCAA ${ }^{+/+}$and HFD$\mathrm{BCAA}^{+/-}$mice $(p=0.73 ; p=063 ; p=0.99$ and $p=0.91$; Fig. $7 B-G$ ) were detected, showing that the partial deficiency in BCAA is not sufficient to reverse glucose metabolism impairments.

As regards behavioral consequences, we reported that the locomotor activity was similar in the different experimental groups 
A

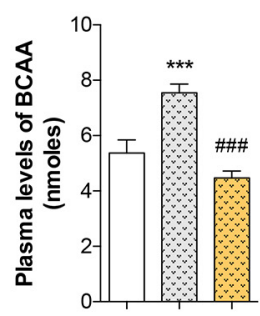

D

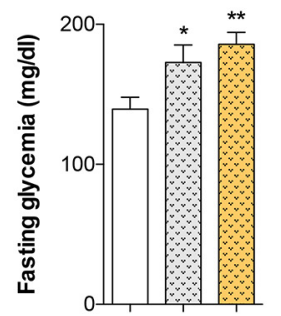

$\mathbf{F}$

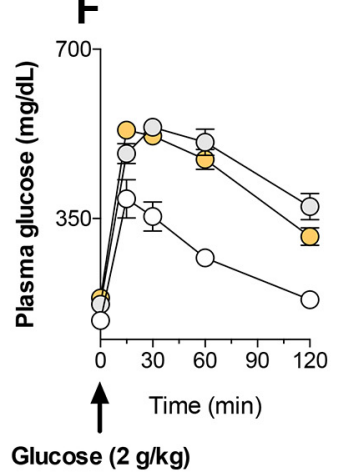

B -O- HFD-BCAA+/-

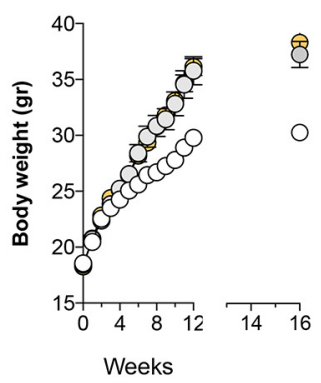

E

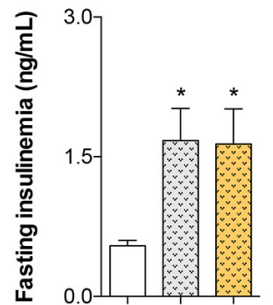

G

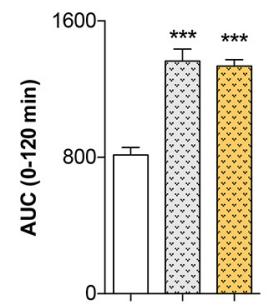
-O- STD -O- HFD-BCAA+/+

\section{C}

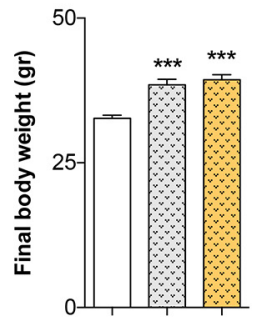

$\mathrm{BCAA}^{+/+}$mice $(p=0.04)$ but not in

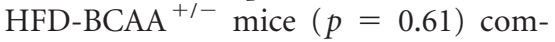
pared with STD mice in the ST, and a significant difference was observed between the latter groups ( $p=0.019$; Fig. $8 H)$. Together, these results led us to envision that deficiency in BCAA might exert antidepressant-like properties while maintaining a high level of anxiety.

In a last series of experiments, we asked how such deficiency in amino acids impacts the response to an acute administration of Flx in the TST. A few days after the first session of TST, we resubmitted the same animals to this procedure and found that a single administration of Flx significantly decreased the percentage of time of immobility in controls $(p=0.03)$ but not in HFD-BCAA ${ }^{+/+}$mice $(p=0.37$; Fig. $9)$. The antidepressant-like effect of Flx was fully restored in HFD-BCAA ${ }^{+/-}$mice ( $p=0.009$; Fig. 9).

\section{Discussion}

This study was designed to determine the neurobehavioral effects of Met in mice fed an HFD and to decipher its putative mechanism of action focusing on the serotonergic system and its projections to the hippocampus, a brain region morphologically and functionally affected in major depression (MacQueen and Frodl, 2011). One of the most remarkable results reported herein is the fact that HFDinduced peripheral IR was accompanied by elevated levels of circulating BCAAs. In the CNS, HFD impaired both the electrical properties of DR 5-HT neurons and 5-HT release, resulting in altered emotionally related behaviors, whereas Met improved all these peripheral and central parameters. Because changes in plasma BCAAs are known to limit tryptophan availability into the brain, we also provided evidence that partial deficiency of BCAAs in diet is sufficient to exert antidepressant-like activity.

(Fig. $8 A$ ). In the EPM, HFD-BCAA ${ }^{+/+}$and HFD-BCAA ${ }^{+/-}$mice displayed a decrease in time $(p=0.04$ and $p=0.03)$ and/or entries in open arms $(p=0.53$ and $p=0.013$; Fig. $8 B, C)$ compared with STD mice. No differences between HFD-BCAA ${ }^{+/+}$ and HFD-BCAA ${ }^{+/-}$mice were detected $(p=0.82$ and $p=0.12)$. In the NSF, although a significant increase in latency to feed was detected in HFD-BCAA ${ }^{+/+}$and HFD-BCAA ${ }^{+/-}$mice compared with STD mice ( $p=0.0002$ and $p=0.0065$; Fig. $8 D)$, both groups displayed similar responses in this paradigm $(p=0.35)$. The latency to eat in the home cage was the same in all experimental groups (Fig. 8E), whereas food home cage consumption based on caloric value consumed was higher in HFD-BCAA ${ }^{+/+}$and HFD$\mathrm{BCAA}^{+/-}$mice compared with STD mice, but did not reach statistical significance (Fig. $8 F$ ). In the TST, a significant decrease in the time of immobility was detected in HFD-BCAA ${ }^{+/-}$mice compared with HFD-BCAA ${ }^{+/+}$mice $(p=0.021$; Fig. $8 G)$. Finally, we showed a higher latency of first grooming in HFD-
It is now well accepted that in homogenous C57BL/6J mice, HFD feeding leads to IR (Burcelin et al., 2002). In agreement with this finding, we reported that exposure to an HFD for 16 weeks elicits glucose metabolic impairments. Met, which belongs to a class of insulin-sensitizing drugs, significantly decreased body weight and improved peripheral IR in mice fed an HFD. Its beneficial effects on peripheral metabolism have been attributed to several peripheral processes including the activation of AMPactivated protein kinase (AMPK) pathway, reduction in hepatic gluconeogenesis, and stimulation of glucose uptake in skeletal muscle (Graham et al., 2011). Interestingly, increased IR drives higher circulating fasting BCAA levels (Mahendran et al., 2017), while rats fed a diet high in BCAAs displayed increased rates of IR (Newgard et al., 2009; Zhao et al., 2016). Here, we demonstrated that HFD mice displayed elevated plasma levels of BCAAs, whereas Met reversed this parameter. Interestingly, 5-HT synthe- 
sis in neurons can be influenced by tryptophan uptake into the brain, which occurs through the LAT1 on the BBB that it shares with the BCAAs (Yamamoto and Newsholme, 2000; Fernstrom, 1983, 2013). Thus, we hypothesized that chronic exposure to an HFD could raise plasma BCAA concentrations sufficiently to limit the uptake of tryptophan into the brain as a result of the competition between amino acids, and thereby reduce neuronal 5-HT synthesis and release from nerve terminals. This is consistent with findings reporting that supplementation in BCAAs reduced brain 5-HT content in rats (Choi et al., 2013) and induced depressive-like symptoms in rodents such as anxiety (Coppola et al., 2013) or anhedonia (Scaini et al., 2014). By attenuating circulating BCAA levels, Met could favor tryptophan availability in the brain and thereby positively reverberate on central 5-HT tone. In an attempt to confirm this assumption and to provide a more valuable insight into the impact of the modulation of circulating BCAAs on the activity of the serotonergic system, electrophysiological and microdialysis experiments were conducted.

In vivo electrophysiological experiments indicated that an HFD did not modify the basal firing rate of DR 5-HT neurons, whereas patch-clamp recordings pointed out that the intrinsic properties of these neurons were significantly impaired. It is plausible that the altered excitability observed in patch-clamp recordings would not affect the basal firing rate but would rather limit DR neuron activation in response to diverse stimuli that notably increased norepinephrine release, which is known to accelerate the pacemaker activity of 5-HT neurons in an $\alpha 1$ adrenoceptor-dependent manner (Aghajanian, 1985). Accordingly, we found that the phenylephrine-induced increased firing rate is blunted after HFD feeding. Met increased the firing rate of DR 5-HT neurons and reversed the impairments of electrical parameters detected in HFD mice. These electrophysiological data parallel the altered extracellular 5-HT levels ([5-HT] ext) in the vHP of mice fed an HFD. Indeed, using in vivo microdialysis, we reported a twofold decrease in basal extracellular [5-HT] ext in HFD mice. However, Met failed to reverse this neurochemical response. Because 5-HT outflow measured by microdialysis reflects a balance between 5-HT uptake and release (Guiard et al., 2006), we assumed that any increase in 5-HT release at the nerve terminals may be counterbalanced by an active 5-HT reuptake process. If this assumption is correct, the stimulating effects of Met on basal extracellular 5-HT levels would be revealed in the presence of a SERT inhibitor. Accordingly, we showed that the acute administration of Flx elicited a greater increase in hippocampal [5-HT] ext in HFD-Met mice than in HFD-Veh.

We next questioned the effects of Met on anxiety- and depressive-like phenotypes, which are finely regulated by $5-\mathrm{HT}$
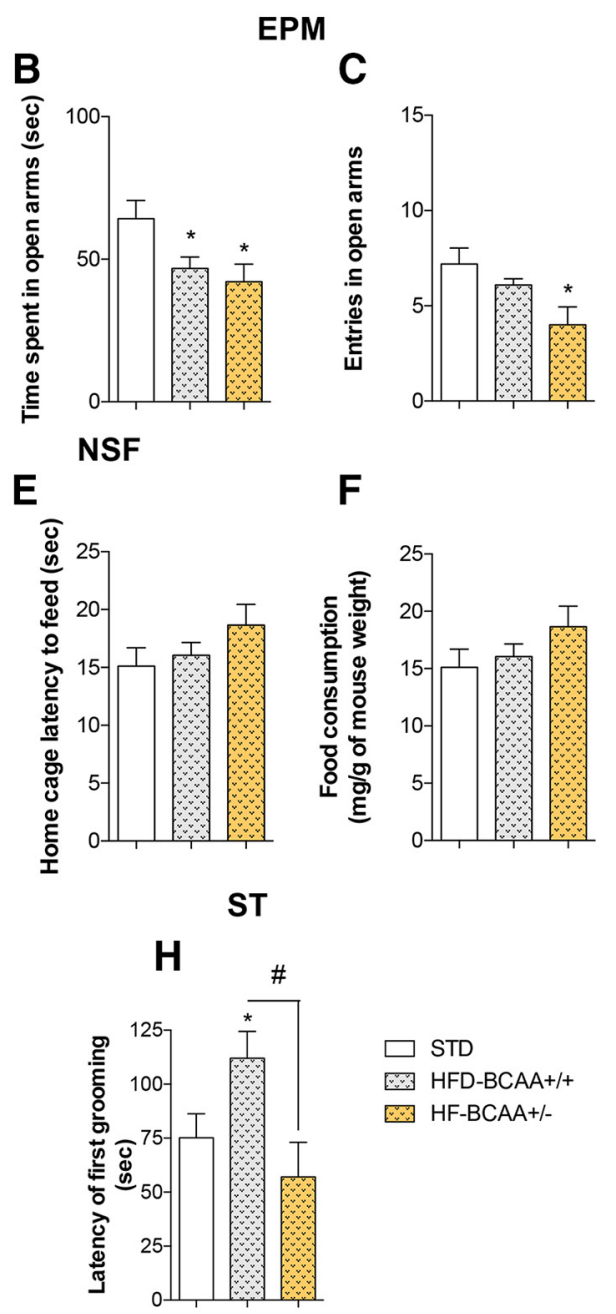

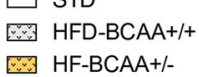

Figure 8. Partial deficiency in BCAAs promotes antidepressant-like effects in mice fed an HFD. Two groups of mice were fed an HFD with a normal or reduced content of branched-chain amino acids (HFD-BCAA ${ }^{+/+}$and HFD-BCAA ${ }^{+/-}$; respectively). $\boldsymbol{A}-\boldsymbol{H}$, The control group of mice was fed an STD. Data are the mean \pm SEM of total distance traveled in the open field for 10 min $\left(F_{(2,27)}\right.$ , $p=0.74 ; A)$, time spent and the number of entries in open arms $\left(F_{(2,27)}=4.4, p=0.02\right.$; and $F_{(2,27)}=4.7, p=0.016 ; B$ $1.4, p=0.25 ; \boldsymbol{E})$, food home cage consumption based on caloric value consumed $\left(F_{(2,27)}=1.2, p=0.3 ; \boldsymbol{F}\right)$, time of immobility in the tail suspension test $\left(F_{(2,27)}=4.2, p=0.025 ; \boldsymbol{G}\right)$, and latency of first grooming in the splash test $\left(F_{(2,27)}=4.5, p=0.02 ; \boldsymbol{H}\right)$. $n=10$ mice/group. ${ }^{*} p<0.05,{ }^{* *} p<0.01$ and ${ }^{* * *} p<0.001$ : significantly different from STD-Veh group. \#p $<0.05$ : significantly different from HFD-BCAA ${ }^{+/+}$mice.

TST

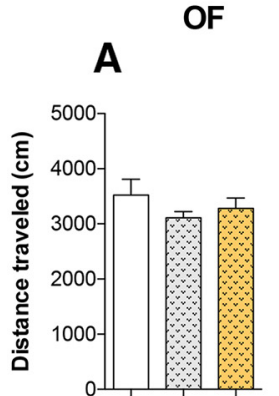

G

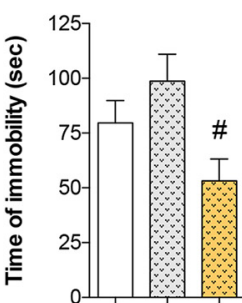




\section{A HFD WITHOUT METFORMIN}

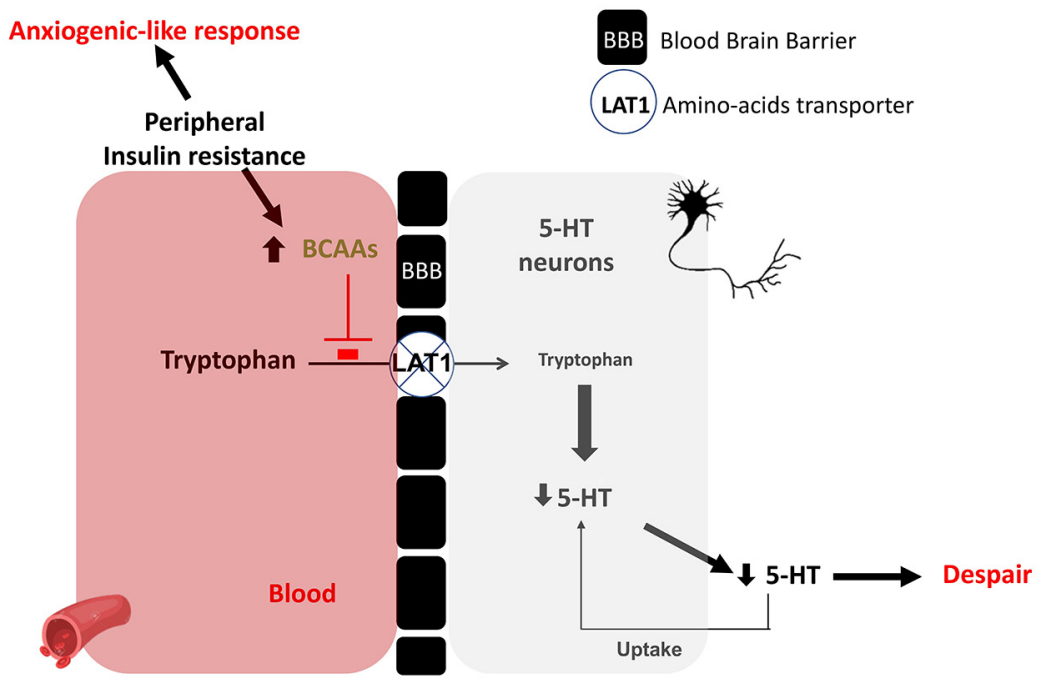

\section{B HFD WITH METFORMIN}

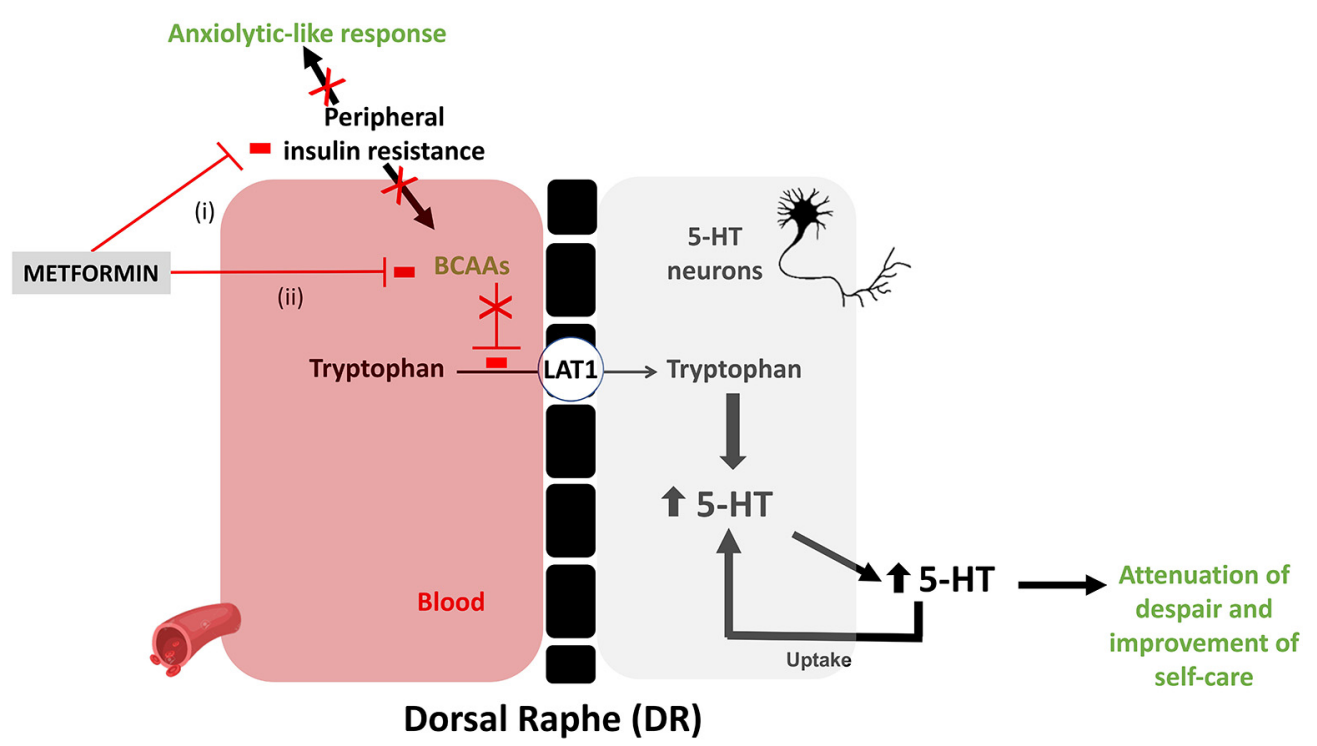

Figure 10. Model underpinning the effects of metformin on depressive symptoms in mice fed an HFD. Peripheral insulin resistance has been associated with anxiogenic-like response, one of the most visible and early symptoms of depression. This metabolic impairment is also responsible for an increase in plasma BCAA (Val, Leu, Isoleu) levels, which limit tryptophan availability in DR 5-HT neurons due to a lower brain penetration across LAT1 expressed on the BBB. A, Such effects are believed to impair DR 5-HT neuronal activity and 5-HT release at the nerve terminals, thereby leading to despair, another symptom of depression. The ability of Met to ameliorate insulin sensitivity represents an important process to promote anxiolytic effects whereas its antidepressant-like effects could rely on both direct (i) and indirect (ii) mechanisms converging toward lower levels of circulating BCAAs. B, The latter mechanism would favor 5-HT neuronal activity and 5-HT release at the nerve terminals, which are key for the antidepressant response. Owing to an active 5-HT reuptake process in the hippocampus of HFD mice treated with Met, the association of this antidiabetic drug with an SSRI could be a new potentiation strategy exerting a wide spectrum of action. Alternatively, the combination of SSRI with a diet poor in BCAAs might be used to relieve depressive symptoms in depressed patients with or without comorbid metabolic disorders.

projections. Our results indicate that mice fed an HFD are prone to develop anxiety, as shown in the EPM and NSF. This result is particularly interesting since anxiety manifests as a predominant feature of depression and can also precede the onset of the pathology (Malhi and Mann, 2018). In a marked contrast, HFD did not influence the time of immobility in the TST, but this result does not rule out the possibility that such a diet caused depressive symptoms beyond anxiety. Indeed, the TST and the forced swim stress have been developed to screen antidepressant-like activity rather than to ascertain depressive-like behavior (Nestler and
Hyman, 2010). The observation that HFD leads to anhedonia and decreased self-care (Dutheil et al., 2016; Zemdegs et al., 2016) reinforces the idea that core symptoms of depression can be also affected by HFD-induced IR (Miyata et al., 2004; Abildgaard et al., 2011; Ho et al., 2012; André et al., 2014; Gupta et al., 2014; Liu et al., 2014; Dutheil et al., 2016; Yang et al., 2016; Zemdegs et al., 2016; Hassan et al., 2018). These data mirror the clinical observations that people experiencing type 2 diabetes and IR are twice as likely to develop depression compared to people without diabetes (Anderson et al., 2001; de Groot et al., 2001). Interestingly, 
the improvement of metabolic parameters induced by prolonged administration of Met in mice fed an HFD were accompanied by a reduction of both anxiety and despair, whereas fluoxetine, the conventional antidepressant drug used herein as a positive control, failed to exert beneficial effects in the EPM. These results concur with previous preclinical studies pointing out that different classes of antidiabetic agents or adiponectin, a hormone exerting insulin-sensitizing action, produces antidepressant-like activities (Ho et al., 2012; Liu et al., 2012; Gupta et al., 2014; Su et al., 2017). In humans, a recent study also reported that Met favors depression recovery in patients with comorbid diabetes unveiling a strong correlation between improvement in plasma glycated hemoglobin levels and depression score (Guo and Lu, 2014).

In light of the latter results, we generated an HFD with a partial deficiency in BCAAs (i.e., HFD-BCAA ${ }^{+/-}$) for which a significant reduction of these plasma amino acids content by $40 \%$ was detected. As previously reported, we found that an HFD deficient in BCAAs did not display an improvement of peripheral IR (White et al., 2016), but reduced despair, and improvement of self-care was detected in HFD-BCAA ${ }^{+l-}$ mice. Finally, we investigated to what extent HFD-BCAA ${ }^{+/-}$influences the response of a single administration of Flx in the TST. Although acute administration of Flx failed to exert an antidepressant-like effect in HFD-BCAA $^{+/+}$mice, a normal response was observed in HFD$\mathrm{BCAA}^{+/-}$mice. The efficacy of antidepressant drugs in a context of T2D and IR both in humans and rodents has been subjected to only few investigations, and no consistent conclusions have been provided (Anderson et al., 2010; Bryan et al., 2010; Isingrini et al., 2010; Gois et al., 2014; Zemdegs et al., 2016).

The present study proposes a new antidepressant strategy based on chronic treatment with Met, which acts, at least in part, by reducing circulating levels of BCAAs and by stimulating 5-HT release in the vHP (Fig. 10). It is important to emphasize that an improvement of brain IR could represent another mechanism underlying the beneficial action of Met. Indeed, the brain is endowed with a high density of insulin receptors (Kleinridders et al., 2014), and growing evidence emphasizes their role in the regulation of brain monoaminergic transmission (Kleinridders et al., 2015) and signaling (Papazoglou et al., 2015). It should also be borne in mind that Met crosses the BBB and has several beneficial effects in the brain such as anti-inflammatory and neuroprotective effects (Łabuzek et al., 2010). A possible mechanism underpinning the anxiolytic- and antidepressant-like effects of Met could thus also recruit such properties. Overall, this study supports the fact that the association of Met or a diet poor in BCAAs with an SSRI could be a relevant "add-on" strategy for the comorbidity of metabolic and mental disorders. This hypothesis has been recently tested showing that the association of Flx and Met produced greater improvement of depressive symptoms in rats exposed to chronic stress and an HFD (Khedr et al., 2018). In light of these data, clinical and preclinical studies are also warranted to further evaluate the efficacy of such a potentiation strategy in depressed patients or in relevant animal models without metabolic comorbidities. In this prospect, a recent study shows that Met produces antidepressant-like activities given either alone (Liu et al., 2019) or in combination with Flx (Poggini et al., 2019) in chronically stressed animals.

\section{References}

Abildgaard A, Solskov L, Volke V, Harvey BH, Lund S, Wegener G (2011) A high-fat diet exacerbates depressive-like behavior in the flinders sensitive line (FSL) rat, a genetic model of depression. Psychoneuroendocrinology 36:623-633.
Aghajanian GK (1985) Modulation of a transient outward current in serotonergic neurons by alpha 1-adrenoceptors. Nature 315:501-503.

Anderson RJ, Freedland KE, Clouse RE, Lustman PJ (2001) The prevalence of comorbid depression in adults with diabetes: a meta-analysis. Diabetes Care 24:1069-1078.

Anderson RJ, Gott BM, Sayuk GS, Freedland KE, Lustman PJ (2010) Antidepressant pharmacotherapy in adults with type 2 diabetes: rates and predictors of initial response. Diabetes Care 33:485-489.

André C, Dinel AL, Ferreira G, Layé S, Castanon N (2014) Diet-induced obesity progressively alters cognition, anxiety-like behavior and lipopolysaccharide-induced depressive-like behavior: focus on brain indoleamine 2,3-dioxygenase activation. Brain Behav Immun 41:10-21.

Asor E, Stempler S, Avital A, Klein E, Ruppin E, Ben-Shachar D (2015) The role of branched chain amino acid and tryptophan metabolism in rat's behavioral diversity: intertwined peripheral and brain effects. Eur Neuropsychopharmacol 25:1695-1705.

Bryan C, Songer T, Brooks MM, Rush AJ, Thase ME, Gaynes B, Balasubramani GK, Trivedi MH, Fava M, Wisniewski SR (2010) The impact of diabetes on depression treatment outcomes. Gen Hosp Psychiatry 32:33-41.

Burcelin R, Crivelli V, Dacosta A, Roy-Tirelli A, Thorens B (2002) Heterogeneous metabolic adaptation of $\mathrm{C} 57 \mathrm{BL} / 6 \mathrm{~J}$ mice to high-fat diet. AM J Physiol Endocrinol Metab 282:E834-E842.

Choi S, Disilvio B, Fernstrom MH, Fernstrom JD (2013) Oral branchedchain amino acid supplements that reduce brain serotonin during exercise in rats also lower brain catecholamines. Amino Acids 45:1133-1142.

Coppola A, Wenner BR, Ilkayeva O, Stevens RD, Maggioni M, Slotkin TA, Levin ED, Newgard CB (2013) Branched-chain amino acids alter neurobehavioral function in rats. Am J Physiol Endocrinol Metab 304:E405E413.

David DJ, Samuels BA, Rainer Q, Wang JW, Marsteller D, Mendez I, Drew M, Craig DA, Guiard BP, Guilloux JP, Artymyshyn RP, Gardier AM, Gerald C, Antonijevic IA, Leonardo ED, Hen R (2009) Neurogenesisdependent and -independent effects of fluoxetine in an animal model of anxiety/depression. Neuron 62:479-493.

de Groot M, Anderson R, Freedland KE, Clouse RE, Lustman PJ (2001) Association of depression and diabetes complications: a meta-analysis. Psychosom Med 63:619-630.

Derkach KV, Bondareva VM, Chistyakova OV, Berstein LM, Shpakov AO (2015) The effect of long-term intranasal serotonin treatment on metabolic parameters and hormonal signaling in rats with high-fat diet/lowdose streptozotocin-induced type 2 diabetes. Int J Endocrinol 2015: 245459.

Dinel AL, André C, Aubert A, Ferreira G, Layé S, Castanon N (2014) Lipopolysaccharide-induced brain activation of the indoleamine 2,3dioxygenase and depressive-like behavior are impaired in a mouse model of metabolic syndrome. Psychoneuroendocrinology 40:48-59.

Dutheil S, Ota KT, Wohleb ES, Rasmussen K, Duman RS (2016) High-fat diet induced anxiety and anhedonia: impact on brain homeostasis and inflammation. Neuropsychopharmacology 41:1874-1887.

Fellendorf FT, Platzer M, Pilz R, Rieger A, Kapfhammer HP, Mangge H, Dalkner N, Zelzer S, Meinitzer A, Birner A, Bengesser SA, Queissner R, Hamm C, Hartleb R, Reininghaus EZ (2018) Branched-chain amino acids are associated with metabolic parameters in bipolar disorder. World J Biol Psychiatry. Advance online publication. Retrieved May 23, 2019. doi:10.1080/15622975.2018.1487077.

Fernstrom JD (1983) Role of precursor availability in control of monoamine biosynthesis in brain. Physiol Rev 63:484-546.

Fernstrom JD (2013) Large neutral amino acids: dietary effects on brain neurochemistry and function. Amino Acids 45:419-430.

Gannon NP, Schnuck JK, Vaughan RA (2018) BCAA Metabolism and Insulin Sensitivity — dysregulated by metabolic status? Mol Nutr Food Res 62:e1700756.

Gois C, Dias VV, Carmo I, Duarte R, Ferro A, Santos AL, Sousa F, Barbosa A (2014) Treatment response in type 2 diabetes patients with major depression. Clin Psychol Psychother 21:39-48.

Graham GG, Punt J, Arora M, Day RO, Doogue MP, Duong JK, Furlong TJ, Greenfield JR, Greenup LC, Kirkpatrick CM, Ray JE, Timmins P, Williams KM (2011) Clinical pharmacokinetics of metformin. Clin Pharmacokinet 50:81-98.

Guiard BP, Lanfumey L, Gardier AM (2006) Microdialysis approach to study serotonin outflow in mice following selective serotonin reuptake 
inhibitors and substance P (neurokinin 1) receptor antagonist administration: a review. Curr Drug Targets 7:187-201.

Guo M, Lu XY (2014) Leptin receptor deficiency confers resistance to behavioral effects of fluoxetine and desipramine via separable substrates. Transl Psychiatry 4:e486.

Gupta D, Radhakrishnan M, Kurhe Y (2014) Insulin reverses anxiety-like behavior evoked by streptozotocin-induced diabetes in mice. Metab Brain Dis 29:737-746.

Hassan AM, Mancano G, Kashofer K, Fröhlich EE, Matak A, Mayerhofer R, Reichmann F, Olivares M, Neyrinck AM, Delzenne NM, Claus SP, Holzer P (2018) High-fat diet induces depression-like behaviour in mice associated with changes in microbiome, neuropeptide $\mathrm{Y}$, and brain metabolome. Nutr Neurosci. Advance online publication. Retrieved May 23, 2019. doi:10.1080/1028415X.2018.1465713.

Herrera-Marquez R, Hernandez-Rodriguez J, Medina-Serrano J, BoyzoMontes de Oca A, Manjarrez-Gutierrez G (2011) Association of metabolic syndrome with reduced central serotonergic activity. Metab Brain Dis 26:29-35.

Ho N, Balu DT, Hilario MR, Blendy JA, Lucki I (2012) Depressive phenotypes evoked by experimental diabetes are reversed by insulin. Physiol Behav 105:702-708.

Isingrini E, Camus V, Le Guisquet AM, Pingaud M, Devers S, Belzung C (2010) Association between repeated unpredictable chronic mild stress (UCMS) procedures with a high fat diet: a model of fluoxetine resistance in mice. PLoS One 5:e10404.

Khedr SA, Elmelgy AA, El-Kharashi OA, Abd-Alkhalek HA, Louka ML, Sallam HA, Aboul-Fotouh S (2018) Metformin potentiates cognitive and antidepressant effects of fluoxetine in rats exposed to chronic restraint stress and high fat diet: potential involvement of hippocampal c-jun repression. Naunyn Schmiedebergs Arch Pharmacol 391:407-422.

Kim M, Bae S, Lim KM (2013) Impact of high fat diet-induced obesity on the plasma levels of monoamine neurotransmitters in C57BL/6 mice. Biomol Ther (Seoul) 21:476-480.

Kiyasova V, Fernandez SP, Laine J, Stankovski L, Muzerelle A, Doly S, Gaspar P (2011) A genetically defined morphologically and functionally unique subset of 5-HT neurons in the mouse raphe nuclei. J Neurosci 31:27562768.

Kleinridders A, Ferris HA, Cai W, Kahn CR (2014) Insulin action in brain regulates systemic metabolism and brain function. Diabetes 63:22322243.

Kleinridders A, Cai W, Cappellucci L, Ghazarian A, Collins WR, Vienberg SG, Pothos EN, Kahn CR (2015) Insulin resistance in brain alters dopamine turnover and causes behavioral disorders. Proc Natl Acad Sci U S A 112: 3463-3468.

Kloiber S, Kohli MA, Brueckl T, Ripke S, Ising M, Uhr M, Menke A, Unschuld PG, Horstmann S, Salyakina D, Muller-Myhsok B, Binder EB, Holsboer F, Lucae S (2010) Variations in tryptophan hydroxylase 2 linked to decreased serotonergic activity are associated with elevated risk for metabolic syndrome in depression. Mol Psychiatry 15:736-747.

Łabuzek K, Liber S, Gabryel B, Okopień B (2010) Metformin has adenosinemonophosphate activated protein kinase (AMPK)-independent effects on LPS-stimulated rat primary microglial cultures. Pharmacol Rep 62: 827-848.

Lang UE, Günther L, Scheuch K, Klein J, Eckhart S, Hellweg R, Danker-Hopfe $\mathrm{H}$, Oehler J (2009) Higher BDNF concentrations in the hippocampus and cortex of an aggressive mouse strain. Behav Brain Res 197:246-249.

Last D, Alsop DC, Abduljalil AM, Marquis RP, de Bazelaire C, Hu K, Cavallerano J, Novak V (2007) Global and regional effects of type 2 diabetes on brain tissue volumes and cerebral vasoreactivity. Diabetes Care 30:11931199.

Lindqvist A, Mohapel P, Bouter B, Frielingsdorf H, Pizzo D, Brundin P, Erlanson-Albertsson C (2006) High-fat diet impairs hippocampal neurogenesis in male rats. Eur J Neurol 13:1385-1388.

Liu R, Dang W, Jianting M, Su C, Wang H, Chen Y, Tan Q (2012) Citalopram alleviates chronic stress induced depression-like behaviors in rats by activating GSK3beta signaling in dorsal hippocampus. Brain Res 1467: $10-17$.

Liu W, Zhai X, Li H, Ji L (2014) Depression-like behaviors in mice subjected to co-treatment of high-fat diet and corticosterone are ameliorated by AICAR and exercise. J Affect Disord 156:171-177.
Liu W, Liu J, Huang Z, Cui Z, Li L, Liu W, Qi Z (2019) Possible role of GLP-1 in antidepressant effects of metformin and exercise in CUMS mice. J Affect Disord 246:486-497.

MacQueen G, Frodl T (2011) The hippocampus in major depression: evidence for the convergence of the bench and bedside in psychiatric research? Mol Psychiatry 16:252-264.

Mahendran Y, Jonsson A, Have CT, Allin KH, Witte DR, Jørgensen ME, Grarup N, Pedersen O, Kilpeläinen TO, Hansen T (2017) Genetic evidence of a causal effect of insulin resistance on branched-chain amino acid levels. Diabetologia 60:873-878.

Malhi GS, Mann JJ (2018) Depression. Lancet 392:2299-2312.

Matthews DR, Hosker JP, Rudenski AS, Naylor BA, Treacher DF, Turner RC (1985) Homeostasis model assessment: insulin resistance and beta-cell function from fasting plasma glucose and insulin concentrations in man. Diabetologia 28:412-419.

Miyata S, Hirano S, Kamei J (2004) Diabetes attenuates the antidepressantlike effect mediated by the activation of 5-HT1A receptor in the mouse tail suspension test. Neuropsychopharmacology 29:461-469.

Nestler EJ, Hyman SE (2010) Animal models of neuropsychiatric disorders. Nat Neurosci 13:1161-1169.

Newgard CB, An J, Bain JR, Muehlbauer MJ, Stevens RD, Lien LF, Haqq AM, Shah SH, Arlotto M, Slentz CA, Rochon J, Gallup D, Ilkayeva O, Wenner BR, Yancy WS Jr, Eisenson H, Musante G, Surwit RS, Millington DS, Butler MD, et al. (2009) A branched-chain amino acid-related metabolic signature that differentiates obese and lean humans and contributes to insulin resistance. Cell Metab 9:311-326.

Papazoglou IK, Jean A, Gertler A, Taouis M, and Vacher CM (2015) Hippocampal GSK3 $\beta$ as a molecular link between obesity and depression. Mol Neurobiol 52:363-374.

Pardridge WM (1998) Blood-brain barrier carrier-mediated transport and brain metabolism of amino acids. Neurochem Res 23:635-644.

Park HR, Park M, Choi J, Park KY, Chung HY, Lee J (2010) A high-fat diet impairs neurogenesis: involvement of lipid peroxidation and brainderived neurotrophic factor. Neurosci Lett 482:235-239.

Phillips OR, Onopa AK, Zaiko YV, Singh MK (2018) Insulin resistance is associated with smaller brain volumes in a preliminary study of depressed and obese children. Pediatr Diabetes 19:892-897.

Poggini S, Golia MT, Alboni S, Milior G, Sciarria LP, Viglione A, Matte Bon G, Brunello N, Puglisi-Allegra S, Limatola C, Maggi L, Branchi I (2019) Combined fluoxetine and metformin treatment potentiates antidepressant efficacy increasing IGF2 expression in the dorsal hippocampus. Neural Plast 2019:4651031.

Quesseveur G, Gardier AM, Guiard BP (2013) The monoaminergic tripartite synapse: a putative target for currently available antidepressant drugs. Curr Drug Targets 14:1277-1294.

Rasgon NL, Kenna HA (2005) Insulin resistance in depressive disorders and Alzheimer's disease: revisiting the missing link hypothesis. Neurobiol Aging 26 [Suppl 1]:103-107.

Scaini G, Jeremias GC, Furlanetto CB, Dominguini D, Comim CM, Quevedo J, Schuck PF, Ferreira GC, Streck EL (2014) Behavioral responses in rats submitted to chronic administration of branched-chain amino acids. JIMD Rep 13:159-167.

Stranahan AM, Norman ED, Lee K, Cutler RG, Telljohann RS, Egan JM, Mattson MP (2008) Diet-induced insulin resistance impairs hippocampal synaptic plasticity and cognition in middle-aged rats. Hippocampus 18:1085-1088.

Su WJ, Peng W, Gong H, Liu YZ, Zhang Y, Lian YJ, Cao ZY, Wu R, Liu LL, Wang B, Wang YX, Jiang CL (2017) Antidiabetic drug glyburide modulates depressive-like behavior comorbid with insulin resistance. J Neuroinflammation 14:210.

Surget A, Saxe M, Leman S, Ibarguen-Vargas Y, Chalon S, Griebel G, Hen R, Belzung C (2008) Drug-dependent requirement of hippocampal neurogenesis in a model of depression and of antidepressant reversal. Biol Psychiatry 64:293-301.

Wang J, Gallagher D, DeVito LM, Cancino GI, Tsui D, He L, Keller GM, Frankland PW, Kaplan DR, Miller FD (2012) Metformin activates an atypical PKC-CBP pathway to promote neurogenesis and enhance spatial memory formation. Cell Stem Cell 11:23-35.

Weina H, Yuhu N, Christian H, Birong L, Feiyu S, Le W (2018) Liraglutide attenuates the depressive- and anxiety-like behaviour in the corticoste- 
rone induced depression model via improving hippocampal neural plasticity. Brain Res 1694:55-62.

White PJ, Lapworth AL, An J, Wang L, McGarrah RW, Stevens RD, Ilkayeva O, George T, Muehlbauer MJ, Bain JR, Trimmer JK, Brosnan MJ, Rolph TP, Newgard CB (2016) Branched-chain amino acid restriction in zucker-fatty rats improves muscle insulin sensitivity by enhancing efficiency of fatty acid oxidation and acyl-glycine export. Mol Metab 5:538-551.

Yamamoto T, Newsholme EA (2000) Diminished central fatigue by inhibition of the L-system transporter for the uptake of tryptophan. Brain Res Bull 52:35-38.

Yang JL, Liu X, Jiang H, Pan F, Ho CS, Ho RC (2016) The effects of high- fat-diet combined with chronic unpredictable mild stress on depressionlike behavior and Leptin/LepRb in male rats. Sci Rep 6:35239.

Zemdegs J, Quesseveur G, Jarriault D, Pénicaud L, Fioramonti X, Guiard BP (2016) High-fat diet-induced metabolic disorders impairs 5-HT function and anxiety-like behavior in mice. Br J Pharmacol 173:2095-2110.

Zhao X, Han Q, Liu Y, Sun C, Gang X, Wang G (2016) The relationship between branched-chain amino acid related metabolomic signature and insulin resistance: a systematic review. J Diabetes Res 2016:2794591.

Zhong KL, Chen F, Hong H, Ke X, Lv YG, Tang SS, Zhu YB (2018) New views and possibilities of antidiabetic drugs in treating and/or preventing mild cognitive impairment and Alzheimer's disease. Metab Brain Dis 33:1009-1018. 